Modelling the surface mass balance from

GCM output

\title{
The Greenland ice sheet: modelling the surface mass balance from GCM output with a new statistical downscaling technique
}

M. Geyer et al.

M. Geyer ${ }^{1}$, D. Salas Y Melia ${ }^{1}$, E. Brun ${ }^{1}$, and M. Dumont ${ }^{2}$

${ }^{1}$ Météo-France/CNRS, CNRM-GAME UMR3589, Toulouse, France

${ }^{2}$ Météo-France/CNRS, CNRM-GAME UMR3589, CEN, Grenoble, France

Received: 7 June 2013 - Accepted: 12 June 2013 - Published: 27 June 2013

Correspondence to: M. Geyer (mikhail.geyer@meteo.fr)

Published by Copernicus Publications on behalf of the European Geosciences Union.

Title Page 


\section{Abstract}

The aim of this study is to derive a realistic estimation of the Surface Mass Balance (SMB) of the Greenland ice sheet (GrIS) through statistical downscaling of Global Coupled Model (GCM) outputs. To this end, climate simulations performed with the CNRM-

5 CM5.1 Atmosphere-Ocean GCM within the CMIP5 (Coupled Model Intercomparison Project phase 5) framework are used for the period 1850-2300. From the year 2006, two different emission scenarios are considered (RCP4.5

and RCP8.5). Simulations of SMB performed with the detailed snowpack model Crocus driven by CNRM-CM5.1 surface atmospheric forcings serve as a reference. On the basis of these simulations, statistical relationships between total precipitation, snowratio, snowmelt, sublimation and near-surface air temperature are established. This leads to the formulation of SMB variation as a function of temperature variation. Based on this function, a downscaling technique is proposed in order to refine $150 \mathrm{~km}$ horizontal resolution SMB output from CNRM-CM5.1 to a $15 \mathrm{~km}$ resolution grid. This leads

15 to a much better estimation of SMB along the GrIS margins, where steep topography gradients are not correctly represented at low-resolution. For the recent past (19892008), the integrated SMB over the GrIS is respectively 309 and $243 \mathrm{Gtyr}^{-1}$ for raw and downscaled CNRM-CM5.1. In comparison, the Crocus snowpack model forced with ERA-Interim yields a value of $245 \mathrm{Gtyr}^{-1}$. The major part of the remaining discrepancy between Crocus and downscaled CNRM-CM5.1 SMB is due to the different snow albedo representation. The difference between the raw and the downscaled SMB tends to increase with near-surface air temperature via an increase in snowmelt.

\section{Introduction}

Recent observations show the dramatic response of the Greenland Ice Sheet (GrIS) to changing climate conditions: the melting season lasts longer and the ablation area tends to expand (Nghiem et al., 2012; Tedesco et al., 2012). According to GRACE

Modelling the surface mass balance from GCM output

M. Geyer et al.

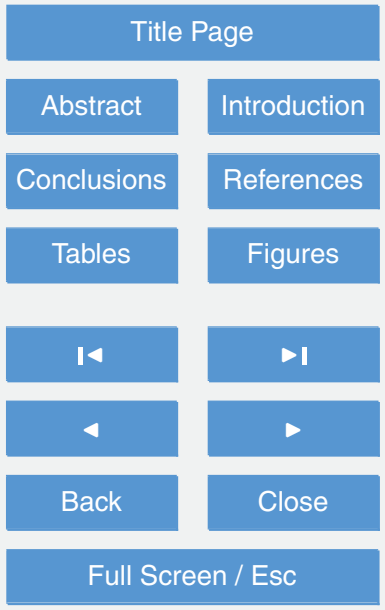

Printer-friendly Version

Interactive Discussion

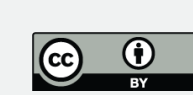


satellite gravimetry observations, for the period 2003-2010, the acceleration of the GrIS mass loss is estimated to $-17 \mathrm{Gtyr}^{-2}$ (Rignot et al., 2012). About half of this mass loss is due to surface mass balance changes (the difference between accumulation and ablation rate). The rest part is mostly due to ice calving (governed by ice-sheet 5 dynamics) and melting at the ocean-ice interface of ice-shelves (Hanna et al., 2008). $\mathrm{SMB}$ can be evaluated using formulations of various degrees of complexity, such as the empiric positive degree day (PDD) method (Reeh, 1991; Tarasov et Peltier, 2002) and surface energy balance models (Bougamont et al., 2007). The latter method is more physically consistent, even though it is much more computationally expensive 10 relative to the positive degree method. Its main advantage is that it represents the different components of the energy exchanges between the snow or ice surface and the atmosphere directly, without using statistical relationships established under present climate conditions. Future changes in downward long-wave and short-wave radiation can be directly converted into SMB changes via surface energy balance models, which is not the case with PDD methods.

SMB is also used as a top boundary condition to simulate the ice flow in ice sheet models. As the characteristic spatial scale of some GrIS ice streams is of the order of a few kilometres or less, it is essential to determine SMB at high spatial resolution, especially close to the ice margin. However, due to limitations in computing resources, contemporary GCMs, which are used for global climate projections, are run at relatively coarse resolution (typically $100 \mathrm{~km}$ for CMIP5 models). Hence the steep slopes and complex orography at the GrIS margins are not resolved. This results in an inaccurate representation of the sharp SMB gradient in these areas. A simple horizontal grid interpolation is not sufficient to overcome this difficulty, which renders the

use of more complex SMB downscaling approaches necessary. The simplest method is the statistical downscaling approach, which consists of establishing statistical relationships between SMB and predictors (e.g. Gregory and Huybrechts 2006; Fettweis et al., 2008; Vizcaino et al., 2010; Helsen et al., 2012). Dynamical downscaling has also been used, but this method is more computationally expensive, especially if long
Modelling the surface mass balance from

GCM output

M. Geyer et al.

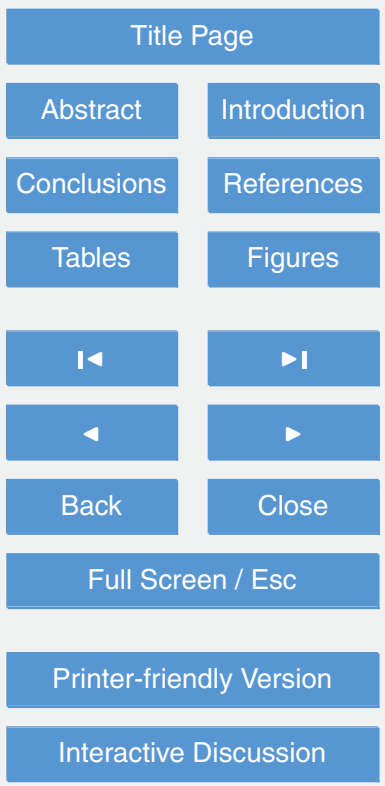


simulations are performed. SMB can be modelled at high-resolution by limited area regional climate models (RCMs) forced at their boundary by low-resolution reanalyses or GCM output (e.g. Box et al., 2004, 2006; Ettema et al., 2009; Rae et al., 2012). An alternative is to use zoomed GCMs over the region of interest (Krinner and Julien, 5 2007), or nested models. Also, mechanistic downscaling models based on simplified atmospheric physics and detailed snowpack modelling allow both the precipitation and surface energy balance related to high-resolution topographic variations to be evaluated (Gallée et al., 2011).

At present, there is still no way to observe the spatial distribution of SMB over the 10 entire ice sheet from satellites as is possible, for example, for the ice sheet albedo
or total mass variations. Numerical simulations are the only means of estimating the
area-average GrIS SMB. The modelled SMB is usually validated over a few sites where human or automatic weather station (AWS) observations are available. An intercomparison of state-of-the-art GrIS SMB evaluations is provided by Rae et al. (2012) for the recent past (1980-2008). They considered four different RCMs (HIRHAM5, HadRM3P, MAR, RACMO) forced with different boundary conditions (HadCM3, ECHAM5, ERA40, ERA-Interim). They simulated GrIS-mean SMBs ranging from 30 to $511 \mathrm{Gtyr}^{-2}$ with rather high interannual variability within the range of 68 to $130 \mathrm{Gtyr}^{-2}$. This is in good agreement with previous studies (Hanna et al., 2008; Wake et al., 2009; Fettweis et al., 2008). However, models still disagree on the sign of the associated trends (from -11.3 to $+5.3 \mathrm{Gtyr}^{-2}$ ), highlighting uncertainties inherent in SMB modelling.

Dynamical downscaling methods are undoubtedly very appropriate for deriving GrIS SMB. However, their computation costs are too high to transform CMIP5 GCM outputs, including large ensembles, into GrIS GCM scenarios. Therefore, we propose a new simple statistical downscaling technique. The models and climate scenarios used, as well as our SMB reference data, are described in Sect. 2. Section 3 explains the procedure of statistical SMB downscaling we developed in detail. The validation of the modelled SMB against observations and MAR simulations is presented in Sect. 4. In Sect. 5, the raw and downscaled GCM SMB are compared with SMB evaluations from

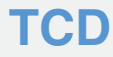

, 3163-3207, 2013

Modelling the surface mass balance from

GCM output

M. Geyer et al.

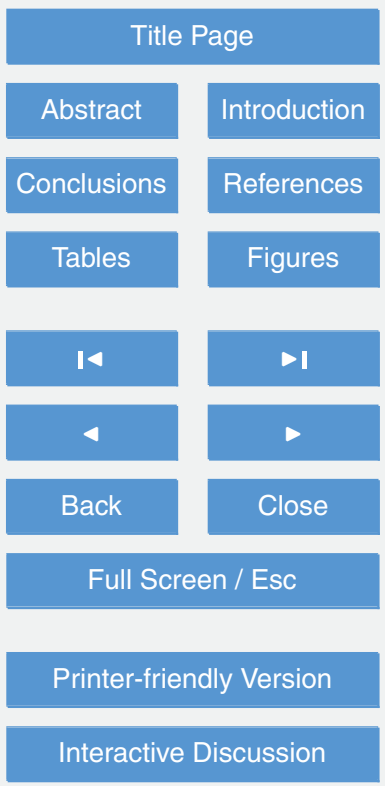


a high-resolution, detailed snow model under two future climate scenarios (RCP4.5 and RCP8.5). The impact of the SMB anomalies on sea level variations is also highlighted in this section. Our results are discussed and conclusions are given in Sect. 6.

\section{Models and data}

5 The future climate data and most of the recent past data used in this study are extracted from climate simulations performed with a modified version of the Atmosphere-Ocean GCM CNRM-CM5.1 global circulation model (Voldoire et al., 2013). CNRM-CM5.1 is one of the models that took part in the CMIP5. CNRM-CM5.1 is based on the oceanatmosphere coupling between NEMO v3.2 (IPSL) and ARPEGE-Climat v5.1 (Météo-

10 France). It includes representations of sea-ice, land-surface and river routing. In the CMIP5 configuration, CNRM-CM simulates the snowpack with the one-layer hybrid snow/soil parameterization D95 (Douville et al., 1995). In this configuration, the albedo over permanent ice cannot drop below 0.8 , which limits the model's capacity to reproduce the snow-albedo feedback over the GrIS. This model has a horizontal resolution 15 of about $150 \mathrm{~km}$; its different components are coupled through the OASIS software (CERFACS, Valcke, 2013). CNRM-CM5.1 is used for applications including seasonal to decadal climate prediction, and long-term simulations (paleoclimates such as the last interglacial or the last glacial maximum, last millennium and future climate).

We used the following CNRM-CM5.1 simulations: pre-industrial (1850 climate, de20 noted as PICTL), historical (1850-2005, denoted as HIST) and two future climate simulations for 2006-2300. The latter were run under the Representative Concentration Pathways emission scenarios (RCP, Moss et al., 2010) 4.5 and 8.5. These two scenarios correspond, respectively, to an increase in radiative forcing of 4.5 and $8.5 \mathrm{Wm}^{-2}$ in 2100 compared to pre-industrial conditions (1850). We produced the 25 required GCM outputs from a series of $10 \mathrm{yr}$ snapshot experiments spanning only a fraction of the 1850-2300 period: $10 \mathrm{yr}$ of preindustrial (1850 constant radiative forcing, PICTL), 1990-1999 (HIST), 2046-2055, 2090-2099, 2190-2199 and 2290-2299

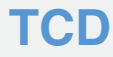

7, 3163-3207, 2013

Modelling the surface mass balance from GCM output

M. Geyer et al.

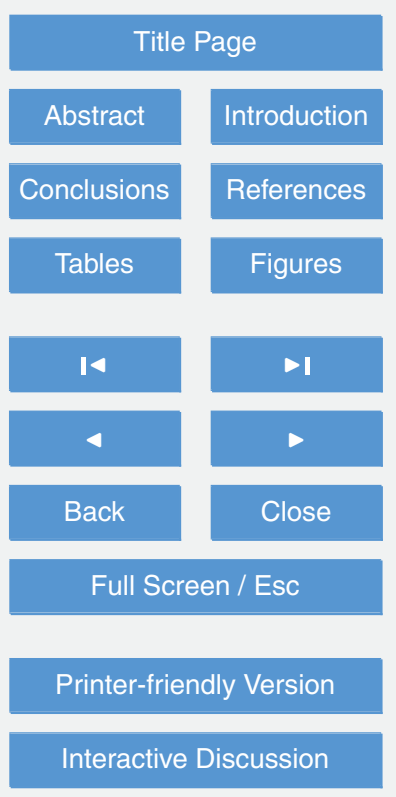


(RCP). We assume that these key $10 \mathrm{yr}$ periods are sufficient to represent transient climate change in the GrIS area correctly. Unless otherwise noted, we will use annual means of the GCM output in the remainder of this work. Time interpolation is applied between the $10 \mathrm{yr}$ averaged snapshots in order to generate continuous data over the 5 entire 1850-2300 period.

The annual mean $\mathrm{SMB}$, denoted hereafter as $B$, can be computed directly from the CNRM-CM output at low horizontal resolution $(150 \mathrm{~km})$ by computing the algebraic sum of the rates of solid precipitation (Ps), snowmelt $(R)$ and sublimation of the snow cover $(\mathrm{Sb})$ :

$10 \quad B=\mathrm{Ps}+R+\mathrm{Sb}$

where all quantities are in $\mathrm{kgm}^{-2} \mathrm{yr}^{-1}$. Contrary to $\mathrm{Ps}, R$ has a negative sign, while $\mathrm{Sb}$ can have both negative (sublimation itself) and positive (condensation) signs.

In order to implement an ice sheet model (GRISLI, Quiquet et al., 2012) in CNRM$\mathrm{CM}$, we need to derive a realistic SMB at the resolution of the ice sheet model $15(15 \mathrm{~km} \times 15 \mathrm{~km})$ from the SMB simulated by CNRM-CM on its own low-resolution grid. To this end, we used the following statistical downscaling learning process, based on the relationship between the CNRM-CM SMB and the SMB simulated by the detailed snow model Crocus (Brun et al., 1992; Vionnet et al., 2012) using forcing conditions from CNRM-CM. To accomplish this, CNRM-CM $3 \mathrm{~h}$ forcing conditions (near-surface $20(2 \mathrm{~m})$ air temperature and specific humidity, total precipitation rate, pressure, short and long solar wave radiation, wind) are downscaled on the $15 \mathrm{~km}$-resolution mesh, using the GrIS topography based on the ETOPO1 database (Amante et Eakins, 2009). The altitude difference between the 150 and the $15 \mathrm{~km}$ resolution topography is taken into account by correcting the air temperature, humidity, pressure and downward long-wave 25 radiation according to Cosgrove et al. (2003). The snow-rain-partition is derived from the elevation of the $1{ }^{\circ} \mathrm{C}$ isotherm level. Crocus simulations are run during the previously mentioned snapshots. To serve as a reference for the CNRM-CM experiments over the past period, an additional Crocus simulation is performed using ERA-Interim

Modelling the surface mass balance from GCM output

M. Geyer et al.

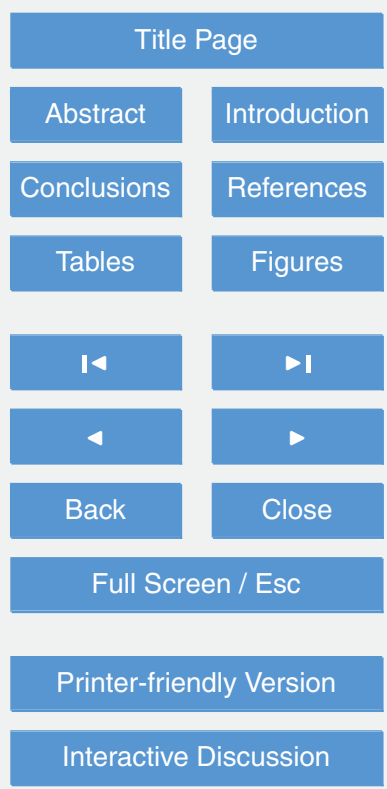


(Dee et al., 2011) forcing fields for 1981-2011. Since Crocus was originally developed for avalanche forecasting, its main feature stems from the dynamical management of its snow layers, which ensures the preservation of a realistic layering of the snowpack. When applied over an ice sheet with up to 20 numerical snow layers in this study, Cro5 cus maintains a clear distinction between the snow layers and the ice layers, making it possible to realistically represent the reappearance of older snow or ice with a lower albedo when the seasonal snow has melted in the ablation area. The regional atmospheric model MAR (e.g. Fettweis et al., 2012; Rae et al., 2012) uses a snow model that implements several key features from Crocus, especially its representation of snow albedo from the metamorphism state and the age of the surface. This means that the use of Crocus over the GrIS already benefits from strong past experience (Lefebre et al., 2003; Tedesco et al., 2012).

We also use the simulations from MAR (X. Fettweis, personal communication, 2013) driven by ERA-Interim lateral boundary conditions for 1981-2011 as a reference. A detailed description of MAR can be found in Fettweis et al. (2012). The present simulations were performed by the version MARv3.2. which corrects some biases found in previous versions of this model (in bare ice albedo, in precipitation (too wet in the interior of ice sheet and too dry along the ice sheet margins) and in temperature (too cold in the interior of ice sheet), X. Fettweis, private communication, 2013). MAR was run at a spatial resolution of $25 \mathrm{~km}$. Based on local SMB gradients (Franco et al., 2012), SMB and water runoff were corrected to $5 \mathrm{~km}$ topography from Bamber et al. (2013). For the accordance with our simulations, these $5 \mathrm{~km}$ outputs were interpolated to $15 \mathrm{~km}$ grid in this work.

Modelling the surface mass balance from GCM output

M. Geyer et al.

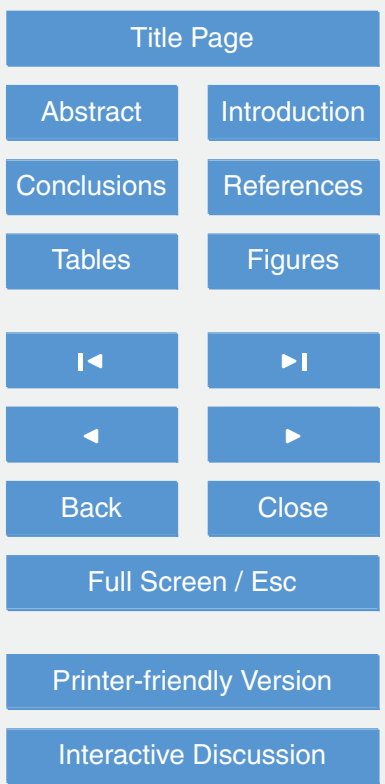




\section{Statistical downscaling}

\subsection{Rationale}

The proposed SMB downscaling method is similar to previous near-surface air temperature downscaling (e.g. Reeh 1991; Tarasov and Peltier, 2002). Hereafter in this study,

5 for the sake of simplicity, near-surface air temperature will be referred to as Surface Air Temperature (SAT). First, the low-resolution SAT field is interpolated to high resolution. Then the SAT is corrected to account for the discrepancy in elevation between the interpolated and the actual surface topography. To this end, a vertical air temperature lapse-rate is used. Even though the temperature lapse-rate coefficient depends on the considered region and altitude, we assume it is constant over Greenland. SMB is a more complex variable, but the same idea may work if the vertical SMB gradient is considered as altitude dependent. Helsen et al. (2012) have followed such an approach to couple a GCM with an ice sheet model. However, such a relationship can be established only locally, as in Helsen et al. (2012), but would certainly not be valid for the entire GrIS. In general, the relationship between SMB and altitude is unreliable, since a given altitude may correspond to very different SMBs. Indeed, SMB is more directly linked to SAT. Hence, in the present study, we seek to establish a relationship between SMB and SAT that represents the mean SMB of the entire GrIS correctly.

According to Eq. (1), we need to express solid precipitation Ps, snowmelt runoff 20 $R$ and sublimation $\mathrm{Sb}$ as functions of SAT, denoted as $T$. To this end, we use the SMB simulations we performed with Crocus. In order to find statistical relationships between the different components of SMB and SAT, the output of these simulations are merged into a single $100 \mathrm{yr}$ series. The corresponding time interval (1850-2300) is wide enough to cover a large temperature range. We use only data associated with 25 grid points located on the GrIS, which makes a total of 7535 grid points for every year of the merged data set.

We note that, unlike snowmelt variations, which usually correlate strongly with SAT variations (Fettweis et al., 2012), the snow precipitation case seems much more

Modelling the surface mass balance from GCM output

M. Geyer et al.

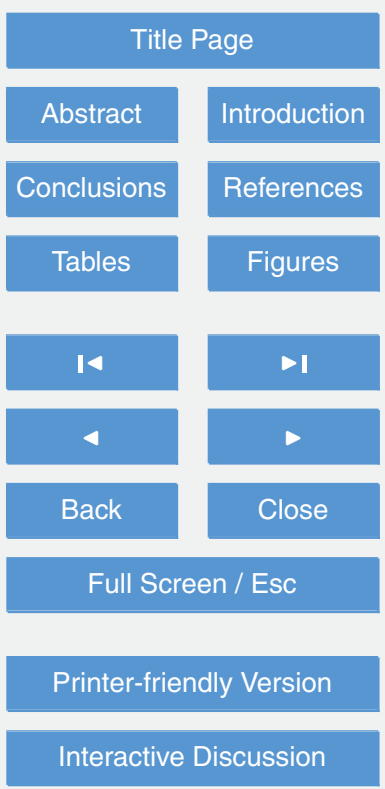


complex, as it depends on many meteorological factors, including atmospheric circulation patterns. Nevertheless, in order to project the precipitation field realistically from a coarse to a fine GrIS topography, we have to determine the tendency of how SAT variations affect Ps. This interaction may not be very strong when GCM does not con5 sider changes in topography. However, when the GrIS topographic changes are taken into account online via ice sheet modelling, these topographic differences may become considerable and significantly affect solid precipitation in long-term future projections.

\subsection{Solid precipitation}

The solid precipitation rate (Ps) can be represented as the product of the total precipitation rate $(\mathrm{Pt})$ and the snow-ratio $(\mathrm{Sr})$ :

$\mathrm{Ps}=\mathrm{Pt} \cdot \mathrm{Sr}$

Hence, determining Ps as a function of SAT $T$ is equivalent to establishing statistical relationships between $\mathrm{Pt}$ and $T$, and between $\mathrm{Sr}$ and $T$.

As expected, the large dispersion seen in Fig. 1a confirms that the total precipitation 15 rate $\mathrm{Pt}$ does not depend solely on $T$, but also on the regional atmospheric circulation. According to the Clausius-Clapeyron relation, the saturation water vapour pressure changes exponentially with temperature (Lawrence, 2005), hinting at the mathematical form of Pt (see Appendix). Hence we fit our data with an exponential:

$\mathrm{Pt}=\mathrm{Pt}_{0} \exp \left(-\gamma_{\mathrm{Pt}}\left(T-T_{\mathrm{Pt}}\right)\right)$

where

$\mathrm{Pt}_{0}=2916.0 \mathrm{~kg} \mathrm{~m}^{-2} \mathrm{yr}^{-1}$

$\gamma_{\mathrm{Pt}}=0.08^{\circ} \mathrm{C}^{-1}$

$T_{\mathrm{Pt}}=7^{\circ} \mathrm{C}$.
TCD

7, 3163-3207, 2013

Modelling the surface mass balance from

GCM output

M. Geyer et al.

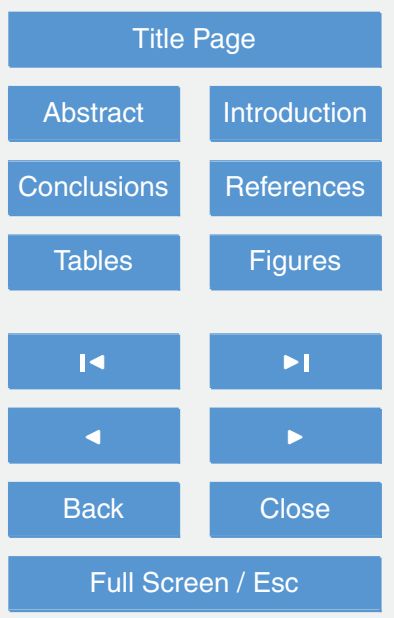

Printer-friendly Version

Interactive Discussion 
This statistical relationship is valid for temperatures ranging from about $-40^{\circ} \mathrm{C}$ to $+10^{\circ} \mathrm{C}$, the range in which data were available. A linear approximation of the exponent of the Clausius-Clapeyron equation (Appendix A) as a function of $T$ shows a slope of $0.073^{\circ} \mathrm{C}^{-1}$, which is rather close to the value we obtained for $\gamma_{\mathrm{Pt}}$. Boer (1993) and 5 Gregory and Huybrechts (2006) obtained slightly smaller values of $0.065^{\circ} \mathrm{C}^{-1}$ and $0.05^{\circ} \mathrm{C}^{-1}$, respectively.

Plotting the snow-ratio data against $T$ (Fig. 1b) reveals a well-known oblique step distribution (e.g. Byun et al., 2007). To fit the data, we assume that precipitation falls only as snow for temperatures below $T_{\mathrm{Ps}}^{\mathrm{min}}=-30^{\circ} \mathrm{C}$. Under this condition, the data can then be approximated by the following function

$$
\begin{array}{ll}
\mathrm{Sr}=1, & T \leq T_{\mathrm{Ps}}^{\min } \\
\mathrm{Sr}=0.5\left(1+\cos \left(\pi \frac{T-T_{\mathrm{Ps}}^{\min }}{T_{\mathrm{Ps}}^{\max }-T_{\mathrm{Ps}}^{\min }}\right)\right), & T_{\mathrm{Ps}}^{\min }<T<T_{\mathrm{Ps}}^{\max } \\
\mathrm{Sr}=0, & T \geq T_{\mathrm{Ps}}^{\max }
\end{array}
$$

where

$T_{\mathrm{Ps}}^{\min }=-30^{\circ} \mathrm{C}$

${ }_{15} T_{\mathrm{Ps}}^{\max }=+10^{\circ} \mathrm{C}$

This means that precipitation falls only as rain for annual mean SAT above $T_{\mathrm{Ps}}^{\max }=$ $+10,{ }^{\circ} \mathrm{C}$.

Plotting the annual mean solid precipitation against annual mean SAT (see Fig. 1c) shows that the snowfall rate is largest when the annual mean SAT is between $-15^{\circ} \mathrm{C}$ and $-5^{\circ} \mathrm{C}$, whereas it is small at positive and extreme negative temperatures. A direct fitting of these data by a polynomial fails, as the resulting function is not able to represent a realistic decay of snowfall for positive temperatures. Using Eq. (1), (3) and (4),

Modelling the surface mass balance from GCM output

M. Geyer et al.

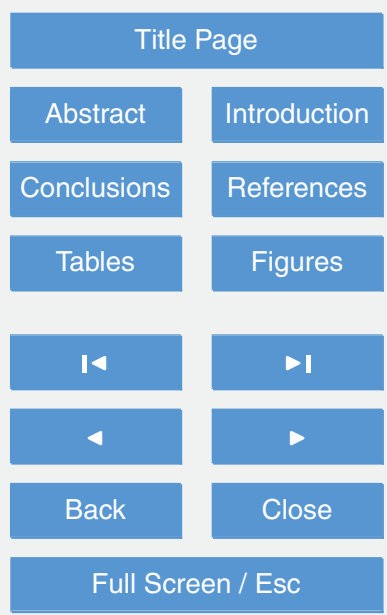

Printer-friendly Version

Interactive Discussion 
the annual mean Ps can be represented as the following function of the annual mean $T$ :

$$
\begin{array}{ll}
\mathrm{Ps}=\mathrm{Pt}_{0} \exp \left(-\gamma_{\mathrm{Pt}}\left(T-T_{\mathrm{Pt}}\right)\right), & T_{\mathrm{Ps}}^{\min } \geq T \\
\mathrm{Ps}=0.5 \mathrm{Pt}_{0} \exp \left(-\gamma_{\mathrm{Pt}}\left(T-T_{\mathrm{Pt}}\right)\right)\left(1+\cos \left(\pi \frac{T-T_{\mathrm{Ps}}^{\min }}{T_{\mathrm{Ps}}^{\max }-T_{\mathrm{Ps}}^{\min }}\right)\right), & T_{\mathrm{Ps}}^{\min }<T<T_{\mathrm{Ps}}^{\max } \\
\mathrm{Ps}=0, & T_{\mathrm{Ps}}^{\max } \leq T
\end{array}
$$

\section{3.3 Snowmelt}

As expected, Fig. 2 shows that the snowmelt tends to increase with SAT (e.g. Franco et al., 2013). Nevertheless, the dispersion of the scatter plot of snowmelt against temperature is rather large, especially when the snowmelt is weak. This is due to the fact that a given negative annual mean SAT may correspond as much to negative daily temperatures throughout the year (no snowmelt in this case) as to negative and positive temperatures (some snowmelt is expected). To fit the data with a polynomial we place two constraints: (i) for $T=-5^{\circ} \mathrm{C}$, the polynomial function should return a snowmelt value $R=-4000 \mathrm{~kg} \mathrm{~m}^{-2} \mathrm{yr}^{-1}$ and (ii) for temperatures below a critical value $T_{R}^{\min }$, the snowmelt is zero; at this point, the snowmelt function is continuously differentiable, hence its slope is zero. The data are then fitted with a polynomial of degree four:

$$
\begin{array}{ll}
R=0, & T<T_{R}^{\min } \\
R=R_{0}+R_{1} T+R_{2} T^{2}+R_{3} T^{2}+R_{4} T^{4}, & T \geq T_{R}^{\min }
\end{array}
$$

Modelling the surface mass balance from GCM output

M. Geyer et al.

Title Page 
where

$T_{R}^{\min }=-21.5^{\circ} \mathrm{C}$

$R_{0}=-6033.681 \mathrm{kgm}^{-2} \mathrm{yr}^{-1}$

$R_{1}=-440.911 \mathrm{~kg} \mathrm{~m}^{-2} \mathrm{yr}^{-1}{ }^{\circ} \mathrm{C}^{-1}$

7, 3163-3207, 2013

${ }_{5} R_{2}=-12.720 \mathrm{kgm}^{-2} \mathrm{yr}^{-1}{ }^{\circ} \mathrm{C}^{-2}$

$R_{3}=-0.697 \mathrm{~kg} \mathrm{~m}^{-2} \mathrm{yr}^{-1}{ }^{\circ} \mathrm{C}^{-3}$

$R_{4}=-0.021 \mathrm{~kg} \mathrm{~m}^{-2} \mathrm{yr}^{-1}{ }^{\circ} \mathrm{C}^{-4}$

Modelling the surface

mass balance from

GCM output

M. Geyer et al.

Using this function, the snowmelt increases less with temperature than in Franco 10 et al. (2013), where an exponential fit was used. In our case, an exponential fit did not correctly match the data.

\subsection{Sublimation}

The annual sublimation data (Fig. 3) does not show any clear relationship to annual mean SAT. This can be explained in part by their strong space variability. Another

15 factor is that our sublimation data aggregates both sublimation itself and condensation. Therefore, for temperatures above $-15^{\circ} \mathrm{C}$, the scatter-plot has a "fish-tailed" pattern. Its upward and downward limbs represent condensation and sublimation, respectively. It would be necessary to fit condensation and sublimation separately. However, our database does not include separate estimations of both processes, so we fitted the sum of sublimation and condensation directly. To this end, we use a simple linear fit:

$\mathrm{Sb}=\mathrm{Sb}_{0}+\mathrm{Sb}_{1} T$,

where

$\mathrm{Sb}_{0}=-9.51 \mathrm{kgm}^{-2} \mathrm{yr}^{-1}$

$\mathrm{Sb}_{1}=-0.36 \mathrm{~kg} \mathrm{~m}^{-2} \mathrm{yr}^{-1}{ }^{\circ} \mathrm{C}^{-1}$

Title Page

Abstract

Introduction

Conclusions

References

Tables

Figures

14

DI

4

Back

Close

Full Screen / Esc

Printer-friendly Version

Interactive Discussion 
This function reflects the fact that, on average, under very low SATs, the ice surface tends to condensate air moisture, whereas an increase in SAT favours surface sublimation. Note that the correlation between the data and the fit is very poor. However, in general the sublimation and condensation processes can be neglected, since they are 5 much smaller than the other terms of the SMB.

\subsection{Surface mass balance}

The annual mean SMB data are plotted against SAT in Fig. 4. The sign of the SMB is determined primarily by the sum of solid precipitation and snowmelt. Statistical relationships to temperature have been established for solid precipitation (Eq. 5), snowmelt 10 (Eq. 6) and sublimation (Eq. 7). Their sum yields SMB (Eq. 1). As shown in Fig. 4, the resulting $B$-function is a correct fit of SMB. This function describes how, on average over the GrIS, the SMB changes as a function of annual mean SAT. It reaches its maximum at $T_{\mathrm{smb}}^{\max } \approx-21.7^{\circ} \mathrm{C}$. From this point, it declines slowly with temperature and decreases rapidly as temperature increases. It becomes negative if the annual mean 15 SAT rises above approximately $-18.3^{\circ} \mathrm{C}$.

In Figs. 1-4 we also plotted the corresponding area-averaged values of the data used in order to compare them with the identified fitted functions. It turns out that these functions also provide reasonable estimations of the GrlS mean mass-balance components as a function of GrIS mean SAT.

\subsection{Downscaling}

The identified statistical relations allow SMB to be downscaled from the CNRM-CM5.1 $150 \mathrm{~km}$-grid to the $15 \mathrm{~km}$ grid. To this end, the low-resolution SMB is interpolated from the low to the high resolution grid. This interpolated SMB needs to be corrected to obtain an SMB with realistic spatial variability. We assume that this correction depends on the altitude difference between the high-resolution topography field $H^{\mathrm{HR}}$ and the low-resolution altitude field $H^{\mathrm{LR}}$ interpolated to high-resolution. This SMB correction
Modelling the surface mass balance from GCM output

M. Geyer et al.

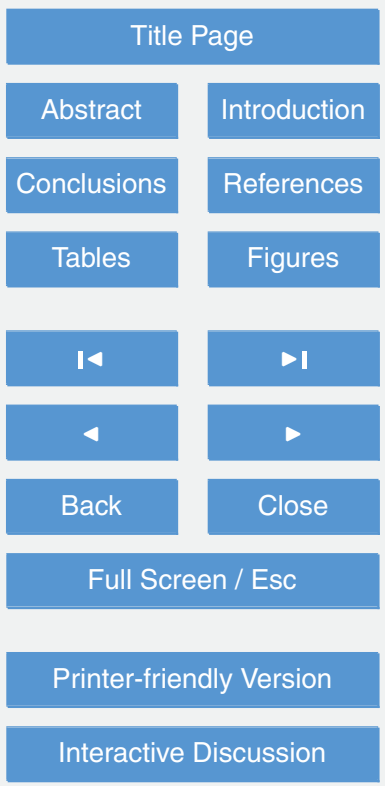


can be written as:

$\Delta B=\frac{\partial B}{\partial H} \Delta H$,

where $\Delta H=H^{\mathrm{HR}}-H^{\mathrm{LR}}$. Eq. (8) can be rewritten as:

7, 3163-3207, 2013

$\Delta B=\frac{\partial B}{\partial T} \frac{\partial T}{\partial H} \Delta H$

5 In Eq. (9), $\frac{\partial H}{\partial T}$ is the vertical air temperature lapse rate. Following Fausto et al. (2009), we approximate this quantity with its mean value over Greenland, denoted as Ir and equal to $-6.309 \mathrm{~km}^{\circ} \mathrm{C}^{-1}$. Hence, we can approximate the SMB correction implied by downscaling as:

$\Delta B=\frac{1}{\operatorname{lr}} \frac{\partial B}{\partial T} \Delta H$

10 Since the statistical fit of $B$ depends strongly on temperature (Fig. 4), the resulting SMB corrections may be very different in regions with similar $\Delta H$ but different SAT annual cycles. In the following section, we will discuss only the impact of the mean SAT on SMB corrections due to altitude changes. Figure 5 illustrates how the SMB, represented by function $B$, changes with altitude corrections within $\pm 600 \mathrm{~m}$, and how these changes depend on the annual mean SAT. We still assume that a change in altitude implies a change in SAT through the lapse-rate coefficient. As previously seen, the function $B$ has a maximum at $T_{\mathrm{smb}}^{\max } \approx-21.7^{\circ} \mathrm{C}$. For lower temperatures, there is little or no snowmelt, and SMB changes are therefore mostly due to changes in solid precipitation rate. For an annual mean SAT lower than $T_{\mathrm{smb}}^{\max }$, an altitude lowering first results in an SMB increase (see curves for $T \leq-22^{\circ} \mathrm{C}$ ). In this case, the temperature increase leads to more snowfall, overcompensating for the associated snowmelt decrease. However, this is no longer the case if the altitude is lowered further and the SMB starts to decrease. For an annual mean SAT higher than $T_{\mathrm{smb}}^{\mathrm{max}}$, a decrease in altitude enhances

Modelling the surface mass balance from

GCM output

M. Geyer et al.

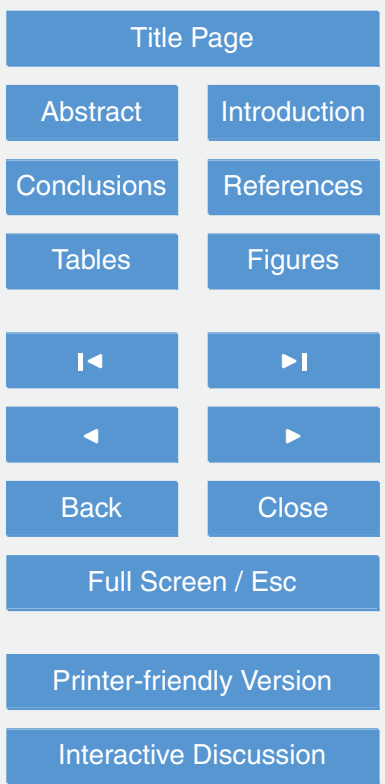


the snowmelt and reduces SMB (see curves for $T \geq-20^{\circ} \mathrm{C}$ ). This example illustrates that the SMB change with altitude is greatly dependent on the annual mean SAT, which is essential to our SMB downscaling method. Indeed, an altitude correction of $-500 \mathrm{~m}$ at two locations with annual SATs of $-10^{\circ} \mathrm{C}$ and $-25^{\circ} \mathrm{C}$ will lead to SMB changes of $5-1$ and $+0.03 \mathrm{~m}$, respectively.

\section{Validation of the modelled SMB against observations and MAR simulations}

The mean 1989-2008 annual SMB was evaluated by several different means, as shown in Fig. 6. The original, simply bilinearly interpolated from $150 \mathrm{~km}$ to $15 \mathrm{~km}$ raw and the downscaled CNRM-CM5.1 SMB are respectively plotted in Fig. 6a-c. The impact of the downscaling is clearly seen along the ice-sheet margins, where SMB is considerably reduced. In contrast, SMB changes are weak in the interior of the GrIS. These changes are consistent with the differences between CNRM-CM5.1's $150 \mathrm{~km}$ resolution topography and the $15 \mathrm{~km}$ resolution topography (Fig. 7). Moreover, according to Fig. 5, for a given altitude change, the higher the annual SAT, the bigger the SMB correction. margin of the GrIS, where the high-resolution topography is significantly lower than its low-resolution counterpart (up to several hundred metres) and the annual mean temperature is relatively high. Conversely, in the interior of the GrIS, the low annual mean temperature does not produce large SMB corrections, even where topographic differ-

ences are considerable. Another important feature of the downscaling is the following: as seen in Fig. $6 \mathrm{~b}$ and $\mathrm{c}$, the downscaling results in a decrease in SMB over the southern dome of the GriS, where accumulation is very high (up to $2 \mathrm{myr}^{-1}$ ) and snowmelt is very low. Unlike in the margin areas, where a decrease in the downscaled SMB is mostly due to an enhancement in the downscaled snowmelt, a decrease in the down-

scaled SMB over this southern dome is due to a decrease in the downscaled solid precipitation.
Modelling the surface mass balance from

GCM output

M. Geyer et al.

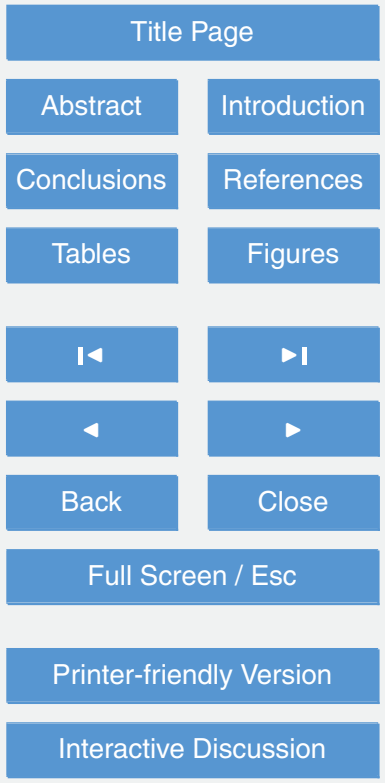


The downscaled CNRM-CM5.1 SMB along the margins still does not reach those negative values which are characteristic of the simulations of Crocus forced by CNRMCM5.1 output atmospheric fields (Fig. 6d). The likely reason for this is the overestimated snow albedo at the margins in CNRM-CM5.1 (Fig. 8a) relative to Crocus 5 (Fig. 8b). This overestimation is due to the large minimum value assumed over permanent ice in CNRM-CM5.1 (0.8); such a large value does not permit a strong positive feedback between albedo and snowmelt. In contrast, the snow albedo modelled by Crocus is much lower at the GrIS margins (Fig. 8b), resulting in enhanced snowmelt. Nevertheless, the area-averaged SMB reveals that downscaling eliminates about $70 \%$ of 10 the average difference between the low- and high-resolution SMB. It is $18.3 \mathrm{~cm} \mathrm{yr}^{-1}$ (integrated value for the whole GrIS is $309 \mathrm{Gt} / \mathrm{y})$ for the raw and $14.4 \mathrm{~cm} \mathrm{yr}^{-1}\left(243 \mathrm{Gtyr}^{-1}\right)$ for the downscaled CNRM-CM5.1 SMB, respectively, and $13.1 \mathrm{cmyr}^{-1}\left(221 \mathrm{Gtyr}^{-1}\right)$ for Crocus (HIST-RCP8.5 scenarios). All these experiments use outputs from CNRMCM5.1 and allow us to assess the impact of the technique used to simulate SMB. As 15 a comparison, Crocus forced with ERA-Interim (Figs. 6e, 8c) over the same time period evaluates an SMB of $14.8 \mathrm{~cm} \mathrm{yr}^{-1}\left(245 \mathrm{Gtyr}^{-1}\right)$, which is very close to both the downscaled CNRM-CM5.1 SMB and to the Crocus SMB evaluated on the basis of CNRM-CM5.1 atmospheric output fields. This result is very encouraging for the downscaling method, since the statistical relationships did not use any information from the ERA-Interim/Crocus simulations.

We also compared our results with the SMB evaluated by the RCM MAR driven by ERA-Interim lateral boundary conditions (Figs. 6f, 8d). MAR SMB exhibits a wider band along the western margin of the GrIS with a negative SMB, as well as a stronger snowmelt at this edge. The corresponding area-averaging of MAR SMB 25 yields $16.6 \mathrm{~cm} \mathrm{yr}^{-1}\left(275 \mathrm{Gtyr}^{-1}\right)$. Thus, all the simulations we performed here, as well as those of MAR, produce very close area-average SMB means. They also show similar patterns of SMB spatial distribution over the GrIS, highlighting that the western border of the GrIS has the highest snowmelt. Moreover, our area-averaged SMB evaluations are also very consistent with the SMB range produced by several models
Modelling the surface mass balance from

GCM output

M. Geyer et al.

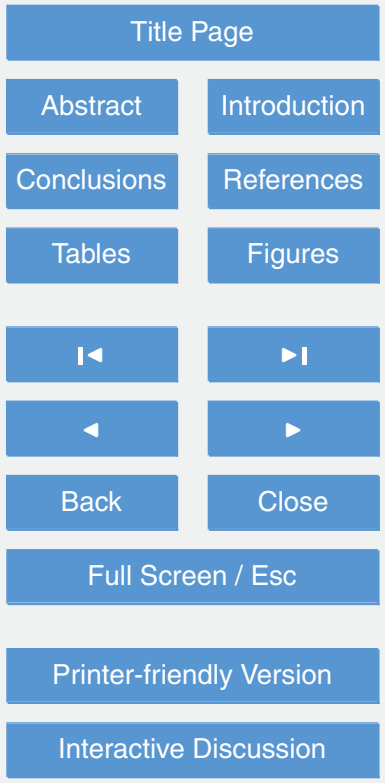


presented in Rae et al. (2012). This provides strong evidence that the statistical solutions found in this work on the basis of Crocus simulations are reliable.

Comparison between SMB (Fig. 6) and the corresponding surface albedo (Fig. 8) evaluations shows that snow albedo has a strong feedback on SMB (e.g. Tedesco 5 et al., 2011, 2012). To study this subject more precisely, and in order to assess our SMB simulations along the margins, we use observations from automatic weather stations (AWS) for the period 2000-2010 (Van de Wal et al., 2012). These weather stations are located on the western part of the GrIS along the K-transect $\left(67^{\circ} \mathrm{N}\right)$. This area is characterized by relatively high ablation (up to $5 \mathrm{myr}^{-1}$ near the margins) and low ac10 cumulation ( $0.3 \mathrm{myr}^{-1}$, Van de Wal et al., 2012). To make a solid representation of the simulated variables along the transect, we average the corresponding values along the $1^{\circ}$ band centred in $67^{\circ} \mathrm{N}$ (from $66.5^{\circ} \mathrm{N}$ to $67.5^{\circ} \mathrm{N}$ ). Cross-sections of CNRM-CM5.1 $\left(150 \times 150 \mathrm{~km}^{2}\right)$, ETOPO1 used in this study as a reference for Crocus $\left(15 \times 15 \mathrm{~km}^{2}\right)$ and MAR $\left(5 \times 5 \mathrm{~km}^{2}\right)$ along the K-transect are shown in Fig. 9a. Both the simulated and the observed SMB are presented in Fig. $9 \mathrm{~b}$ as a function of surface elevation. As seen, the raw CNRM-CM5.1 SMB is in close agreement with the observations for high altitudes $(H>1500 \mathrm{~m})$, but fails in representing the large negative values observed at lower altitudes. As seen from Fig. 9b, relative to CNRM-CM5.1 simulations, the SMB modelled by Crocus is much more consistent with observations. This is especially true when Crocus is forced with ERA-Interim, in spite of the fact that ERA-Interim topography is too smooth, which impacts the quality of its precipitation field. The accuracy of Crocus SMBs is comparable to high-resolution MAR SMB evaluation, which is the closest to the AWS observations (we can also refer for this case to the works from Box et al. (2006) and Krinner and Julien, 2007). Relative to the AWS observations, both Crocus simulations overestimate SMB at lower altitudes, while MAR slightly underestimates SMB over the entire transect.

As shown, the downscaling produces more realistic SMB at low altitudes, even though discrepancies with the observations remain considerable. These discrepancies can probably be explained by a corresponding overestimation of surface albedo. The

Modelling the surface mass balance from GCM output

M. Geyer et al.

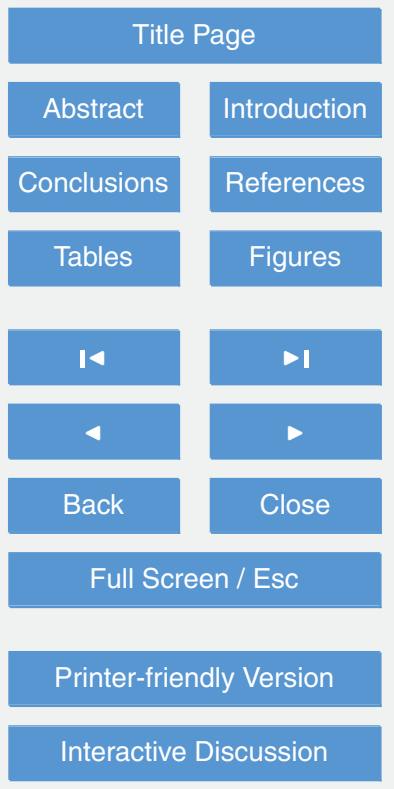


modelled (CNRM-CM5.1, Crocus, MAR) surface snow albedos evaluated along the $\mathrm{K}$-Transect for the summer season are presented in Fig. 9c. We compare them with the corresponding measurements based on the MODerate-resolution Imaging Spectroradiometer (MODIS). Its observational data is based on 16 day albedo products 5 (MCD43C3), which have been evaluated with respect to field measurements on the GrIS (Stroeve et al., 2005). Their root-mean-square error in comparison with field measurements is \pm 0.04 for albedos smaller than 0.07 with high quality flags. The product was reprojected on the same grid as the model, taking great care to remove pixels with low quality flags. We use here the white sky albedos, i.e. the albedo under dif10 fuse illumination, to avoid the effect of varying solar zenith angle. All pixels classified as less than $100 \%$ of snow were also removed from the calculation. Due to the fact that low inclinations of the sun may greatly hamper satellite measurements of albedos (Stroeve et al., 2005; Box et al., 2012), only observations for the summer season are considered here. However, the greatest part of the annual GrIS snowmelt occurs in this 15 period (e.g., Tedesco et al., 2011, 2012).

As seen in Fig. 9c, the albedo modelled by Crocus is generally in good accordance with the MODIS measurements. MAR and Crocus forced by ERA-Interim produce an inferior albedo relative to the MODIS observations for the high altitudes and conversely for the low altitudes. The albedo is slightly overestimated for Crocus forced by CNRMCM5.1 atmospheric outputs over the entire transect. These albedos greatly decline with altitude, decreasing from 0.8 for high latitudes to about 0.5 for lower altitudes. At the same time, CNRM-CM5.1 albedo does not go even below 0.8. Comparison of Fig. 9b and $c$ reveals a strong link between the snow albedo and the correspondent SMB. Thus, the overestimated values of SMB evaluated by CNRM-CM5.1 or by Crocus/CNRM-CM5.1 relative to the SMB observations are well aligned with the corresponding overestimation of surface albedo. This suggests that most of the discrepancy between the observations and the downscaled CNRM-CM5.1 SMB is more likely due to the corresponding albedo discrepancy, rather than the downscaling technique.

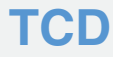

7, 3163-3207, 2013

Modelling the surface mass balance from GCM output

M. Geyer et al.

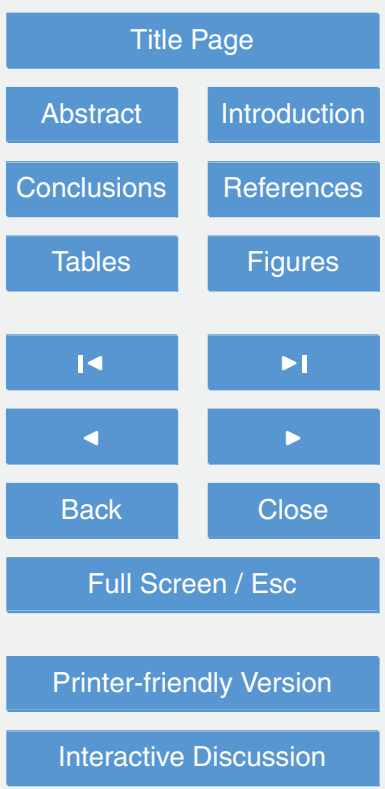




\section{SMB future projections}

In this section we estimate future SMB changes and how the proposed downscaling technique affects SMB under different future climate scenarios. Both RCP4.5 and RCP8.5 future climate scenarios predict a significant SAT rise over the whole GrIS.

5 The two scenarios diverge only after the mid-21st century (Fig. 10). Relative to the end of the 20th century for RCP4.5 (RCP8.5), the annual mean SAT increases by about $2(5){ }^{\circ} \mathrm{C}$ at the end of the 21 st century, $3(11)^{\circ} \mathrm{C}$ at the end of the 22 nd century and $3(12)^{\circ} \mathrm{C}$ at the end of the $23 r d$ century, respectively. As seen, the cold SAT bias over Greenland in CNRM-CM5.1 reaches almost $6^{\circ} \mathrm{C}$ relative to the ERA-Interim/Crocus SAT for 1981-2011. In comparison with the ERA-Interim/Crocus SAT, MAR shows much colder temperatures. This may come from MAR's capacity to perform an actual coupling between a detailed snowpack and the atmosphere, while ERA-Interim may suffer from a poorer representation of the snowpack and a design which does not account for polar physical processes (i.e. cloud microphysics and impacts of stability on turbulent fluxes).

The future climate scenarios project a general increase in solid precipitation (Fig. 11a). We see that the downscaling method reduces the solid precipitation. For the past and present climates, the downscaled precipitation becomes more consistent with the corresponding precipitation of Crocus driven by CNRM-CM5.1 atmospheric fields. Obviously, the different formulations of the definition of solid precipitation in these two models become more significant in the future scenarios and result in a greater disagreement between the simulations. Figure 11a also highlights that the amount of solid precipitation is noticeably higher in ERA-Interim (used by Crocus) and MAR than in the HIST-RCP scenarios used. As relatively to ERA-Interim and MAR, HIST-RCP climate scenarios overestimate solid precipitation on the south-western part of the GrIS southern dome (Fig. 6), the latter are likely to show higher precipitation over the interior.

Modelling the surface mass balance from GCM output

M. Geyer et al.

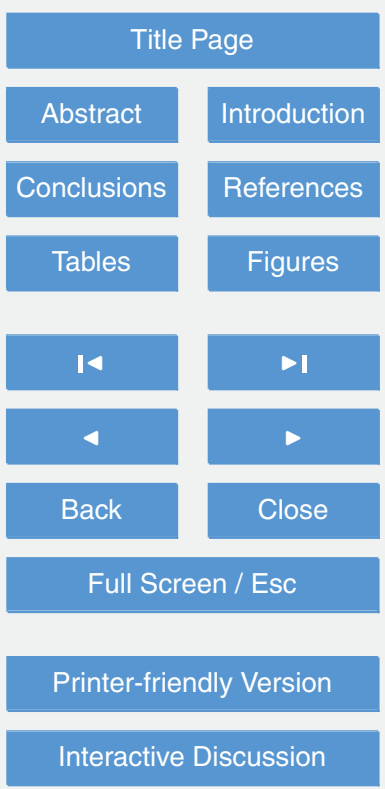


The simulations we performed reveal a non-significant increase in sublimation (Fig. 11b). Though all the simulations show different area-averaged sublimation, its values are insignificant in comparison to solid precipitation or to snowmelt.

An intensification of the snowmelt appears in all the climate scenarios considered 5 (Fig. 11c). As seen in this figure, the downscaling considerably enhances the snowmelt, compared with the raw SMB outputs of CNRM-CM. The downscaled CNRM-CM5.1 and Crocus (forced by CNRM-CM5.1 atmospheric forcings) snowmelts are in good agreement with ERA-Interim/Crocus and MAR snowmelt until the year 2000. Afterwards, the latter show a much more dramatic snowmelt, which is not the case for the simulations 10 based on HIST-RCP scenarios. This provides further evidence that the CMIP5 models underestimate some of the rapid changes experienced by the Arctic cryosphere over the last decade (e.g. Derksen and Brown, 2012; Stroeve et al., 2012).

$\mathrm{SMB}$, which is greatly affected by snowmelt and by solid precipitation, shows a generally negative trend for the both RCP future climate scenarios through the end of the 21st century (Fig. 11d). Subsequently, under RCP4.5, the mean GrIS SMB stabilises and remains positive, close to $+0.1 \mathrm{~m} \mathrm{yr}^{-1}$. In contrast, RCP8.5 projects a strong SMB decline after the 21st century due to the large increase in snowmelt. For this scenario, the increase in snowmelt overcompensates for the corresponding increase in solid precipitation, resulting in a negative area-averaged SMB during the 22nd century. At the end of the 23rd century it decreases further, to $-0.4 \mathrm{~m} \mathrm{yr}^{-1}$.

Note that SMB (as well as solid precipitation and snowmelt) evaluations performed by ERA-Interim/Crocus and MAR are in excellent mutual agreement. They both decrease more rapidly after year 2000 , when snowmelt enhances precipitously. Nevertheless, for the simulated period 1981-2011, ERA-Interim SMBs always remains positive. Similarly to the snowmelt case, the SMB decrease modelled by CNRM-CM5.1 (and similarly by Crocus forced with CNRM-CM5.1) is much more modest than those of ERA-Interim. Figure 11a-d shows that this underestimation of the recent CNRM-CM5.1 SMB decrease is due to the underestimation of snowmelt, which can probably be linked to the
Modelling the surface mass balance from GCM output

M. Geyer et al.

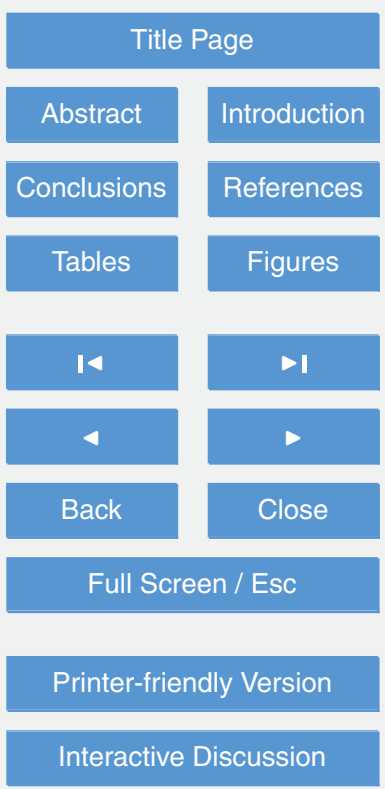


above-mentioned CNRM-CM5.1 cold temperature bias (Fig. 10) and the overestimated summer surface albedo (Figs. 8 and 9c).

As seen from Fig. 11d, downscaling improves the representation of CNRM-CM5.1 $\mathrm{SMB}$, which approaches the SMB evaluated by Crocus. Note, however, that the differ5 ence between the raw and downscaled SMB tends to increase with time. This is due to the fact that the impact of a given altitude correction on SMB increases with SAT, as discussed in Sect. 3.6 (see also Fig. 5), which is the case for both future climate scenarios considered here, but especially for RCP8.5. Conversely, over the period 1850-2000, when SAT changes are weak, the difference between the raw and downscaled SMB is o almost constant (Fig. 11d).

Crocus forced by CNRM-CM5.1 atmospheric forcings always projects a lower SMB than itself CNRM-CM5.1. As was already shown in Sect. 4, this is probably due to the different snow albedo representations used in these two models. As the lowest snow albedo in CNRM-CM5.1 is prescribed to 0.8 , the feedback of surface melting on $\mathrm{SMB}$ through a decrease in snow albedo is not represented. In contrast, this feedback plays a major role in Crocus, triggering earlier seasonal snow surface melting and the reappearance of below-the-surface old ice in summer. The latter explains the greater decrease of RCP8.5 Crocus snowmelt (Fig. 11c) and SMB (Fig. 11d) projections for the 21 st and 22nd century relative to CNRM-CM5.1 modelling. However, the further continuous snowfall augmentation eventually leads to a rise in the average GrIS snow albedo for the 23rd century (not shown here). For Crocus modelling, which simulates the refreezing of liquid water in the firn in winter, this results in a corresponding decrease of the mean GrIS snowmelt amplification rate due to acceleration of the meltwater refreeze. This important process, which delays the acceleration of lower SMB values over the higher areas, is not represented in CNRM-CM5.1 (as it does not include the melt-refreeze process).

Another illustration of the impact of downscaling as a function of SAT is provided by Fig. 12. The downscaled CNRM-CM5.1 SMBs under HIST-RCP8.5 scenarios for 20012010 and 2291-2300 are respectively plotted in Fig. 12a and c. As shown, relative to

Modelling the surface mass balance from GCM output

M. Geyer et al.

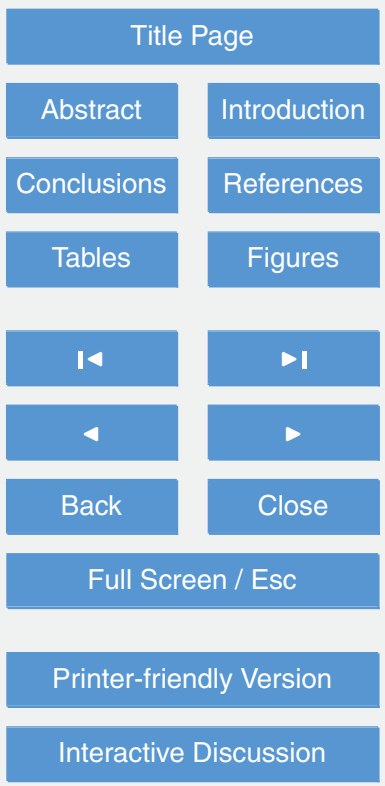


the beginning of the 21st century, the ice loss is considerably enhanced at the margins of the GrIS, particularly in the southwest, reaching a rate of more than one metre per year at the end of the 23 rd century. The differences between the downscaled and raw SMB for 2001-2010 and 2291-2300 are respectively plotted in Fig. 12b and d. Accord5 ing to Eq. (10), these differences are functions of both SAT changes and differences in topography between CNRM-CM5.1 and ETOPO1 (Fig. 7). Since SAT changes are still small in 2001-2010 relative to 1850-1859, the impact of altitude corrections on SMB is notable only at the margins, where altitude corrections are significant (up to several hundred metres). In contrast, since by the end of the 23rd century the SAT increases 10 considerably over the GrIS, the same altitude correction results in a much bigger SMB change, as explained in Sect. 3.6. This is particularly obvious in the area delimited by a box in Fig. 12, where the negative altitude correction is relatively large. In this region, the SMB changes due to downscaling are close to zero at the beginning of the $21 \mathrm{st}$ century (Fig. 12b) and reach $-0.5 \mathrm{myr}^{-1}$ by the end of the $23 \mathrm{rd}$ century (Fig. 12d).

It is practical to convert GrIS SMB changes relative to $1850-1859$ to equivalent global sea level variations. Over the 2001-2010 period, our sea level rise estimation is about $+0.25 \mathrm{mmyr}^{-1}$, based on CROCUS simulations forced by CNRM-CM5.1 output. This is much lower than recent satellite observations of the total GrIS contribution to sea level rise (GRACE $\sim 0.7 \mathrm{mmyr}^{-1}$ in 2006, Rignot et al., 2011; ICESat $\sim 0.65 \mathrm{~mm} \mathrm{yr}^{-1}$ for the period 2003-2008, Sørensen et al., 2011). However, the latter estimations take all types of mass loss (SMB, ice calving, basal melt) into account, whereas our estimations are based only on SMB anomalies. As seen in Fig. 13a, the projected sea level rise rate computed from Crocus SMB anomalies is almost doubled $\left(0.4 \mathrm{~mm} \mathrm{yr}^{-1}, \mathrm{RCP} 4.5\right)$ and quadrupled $\left(0.8 \mathrm{mmyr}^{-1}, \mathrm{RCP} 8.5\right)$ for 2100 . This corresponds to about 3 (RCP4.5) 25 and $4.5 \mathrm{~cm}$ (RCP8.5) of absolute sea level rise for the 21 st century (Fig. 13b). These results are in agreement with Huybrechts et al. (2004), Oerlemans et al. (2005), Meehl et al. (2007), Fettweis et al. (2008), where close estimations of sea level rise based on GrIS SMB anomalies were projected for the A1B scenario. However, our results are underestimated relative to $4 \pm 2 \mathrm{~cm}$ and $9 \pm 4 \mathrm{~cm}$ for the same RCP 4.5 and RCP 8.5
Modelling the surface mass balance from GCM output

M. Geyer et al.

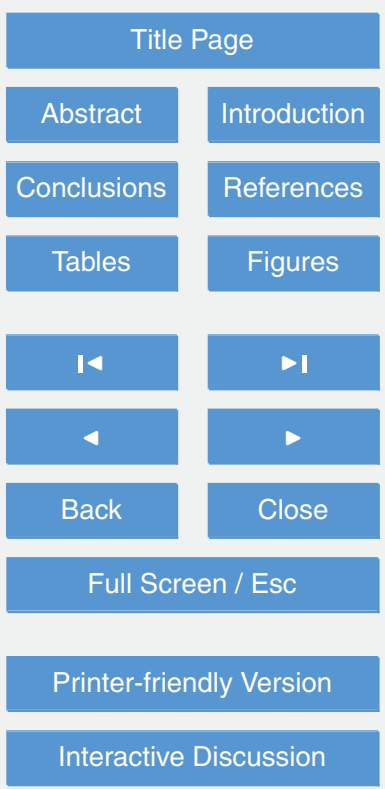


scenarios, respectively, as modelled by Fettweis et al. (2012) on the basis of the RCM MAR. Our underestimation may be due partially to the fact that we used only several $10 \mathrm{yr}$ snapshots of the CNRM-CM5.1 simulations and did not run the entire time period. In any case, as was already shown above, the CNRM-CM5.1 model under HIST-RCP 5 climate scenarios is not capable of fully capturing the ongoing rapid changes occurring over the GrlS for the last decade.

At the end of the 23rd century, with reference to 1850, our Crocus SMB anomalies project $0.4(2.5) \mathrm{mmyr}^{-1}$ of sea level rise rate and $13.5(46) \mathrm{cm}$ absolute sea level rise for the scenario RCP4.5 (RCP8.5). The downscaled CNRM-CM5.1 SMBs produce 10 stronger SMB anomalies than the raw SMB and, as a consequence, higher sea level rise estimations. The downscaling tends to reduce the difference in sea level rise between estimations based on CNRM-CM5.1 and Crocus. For the recent past and the present climate, this effect does not seem to play a significant role in the corresponding SMB anomalies, and as a consequence, in the corresponding sea level variations.

15 However, the downscaling acts distinguishably on SMB anomalies with climate warming. For example, as seen in Fig. 13b, by the end of 23rd century the downscaling gains an additional 3 and $8 \mathrm{~cm}$ of absolute sea level rise for the RCP4.5 and RCP8.5 scenarios, respectively.

It should be noted that the GrIS topography is fixed during our simulations. Therefore, 20 the snowmelt/elevation feedback (Gregory and Huybrechts, 2006) is not considered here. As was shown in Helsen et al. (2012), this feedback amplifies the snowmelt according to the lapse-rate temperature increment when the surface elevation decreases. This means that our evaluations of the GrIS SMB changes are likely underestimated.

\section{Discussion and conclusions}

25 The main goal of SMB downscaling is to turn low-resolution GCM output fields over GrIS into high-resolution SMB fields, taking into account the critical impact of fine topographical features on the SMB. Once the SMB horizontal interpolation is complete,

\section{Modelling the surface mass balance from GCM output \\ M. Geyer et al.}

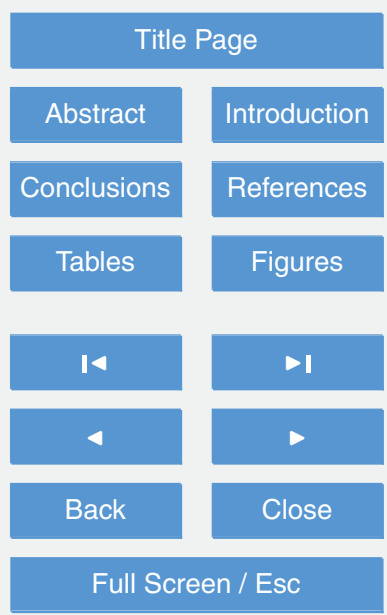

Printer-friendly Version

Interactive Discussion 
downscaling is applied to compute SMB corrections as a function of altitude changes between the coarse and fine grids. In this study, the corrections are computed on an annual basis. To do so, we determined statistical relationships between SAT changes and the changes in the different components of SMB, and assumed that a SAT change 5 is linked to an altitude change through a constant lapse-rate. For the recent past (19812011), Crocus simulations (HIST-RCP climate scenarios), which form the basis for statistical relationships, are in good agreement with the available high-resolution simulations of MAR driven by ERA-Interim lateral boundary conditions. This provides sound evidence that the statistical solutions found here are reliable.

10 The developed downscaling technique offers an improved SMB over most of the GrIS, taking into account changes in small-scale topography. However, it may introduce smoothing effects, since we chose to fit annual mean data with functions of one variable, namely annual mean SAT. The data presents dispersion that can be due either mostly to different SAT annual cycles or spatial variability. In the case of snowmelt,

a given annual mean SAT can correspond to very different SAT annual cycles, and hence very different snowmelts. Thus the annual mean SAT alone is not the best predictor for annual mean snowmelt. Multiple regression on the basis of monthly data may be considered (Such an attempt, not shown here, was made. It demonstrated an expected decrease of the dispersion of the data). Using positive degree-days as a second predictor in addition to annual mean SAT would be a possibility. In the case of precipitation, spatial variability prevails, contributing significantly to scattering the data. Precipitation is one of the components of the Earth's complex hydrological cycle. It is connected to SAT, but also depends heavily on a variety of other different physical characteristics (humidity convergence, solar radiation, etc). A multiple regression of annual mean precipitation based on monthly SAT data would probably not be useful in this case (such an attempt, not shown here, was made. It demonstrated no decrease of the dispersion of the data) and other additional predictors should be found. Therefore, we conclude that although multiple regressions are powerful tools for establishing more reliable statistical laws between snowmelt, precipitation and SAT, they detract
Modelling the surface mass balance from GCM output

M. Geyer et al.

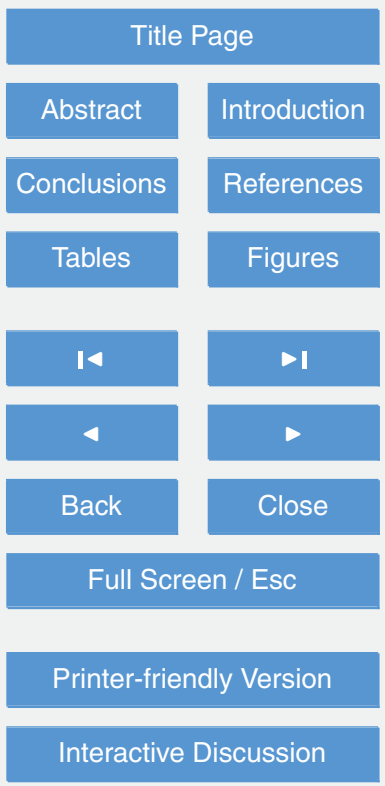


significantly from the simplicity of the procedure, contrary to one of the objectives of this work.

The downscaling technique we developed results in a general decrease of SMB along the ice sheet margins, mostly because of the snowmelt enhancement. As was

5 shown, the differences between the raw and downscaled SMB tend to increase with SAT. For high temperatures, a given altitude decrease results in a stronger snowmelt amplification than for low temperatures. We noted that the representation of snow albedo by CNRM-CM5.1 is not realistic. However, this does not actually affect the relationships found, as the latter were established on the basis of the high-resolution 10 Crocus modelling. A positive outcome from our downscaling technique is that it reduces the discrepancy in GrIS-averaged SMB between raw CNRM-CM5.1 and Crocus SMB by about $70 \%$. As a result, the downscaled low-resolution CNRM-CM5.1 SMB becomes very consistent with high-resolution MAR SMB, which opens very encouraging perspectives for the developed technique.

15 For future climate projections of the GrIS topography's response to upcoming climate change and the consequent impact on sea level rise, it is also important to take into account the feedback between changes in GrIS geometry and SMB (Gregory and Huybrechts, 2006; Helsen et al., 2012). Currently, most global and regional atmosphere/surface climate models do not modify topography online. However, it is possible to account for the impact of GrIS topography changes on SMB as such models are run if these changes are small enough not to affect atmospheric circulation significantly. Assuming this, the SMB can be corrected online following our downscaling technique.

\section{Appendix}

\section{An approximation of the Clausius-Clapeyron equation}

25 A good approximation of the Clausius-Clapeyron relation providing the saturation water vapour pressure in typical atmospheric conditions can be made using the

\section{Modelling the surface mass balance from \\ GCM output \\ M. Geyer et al.}

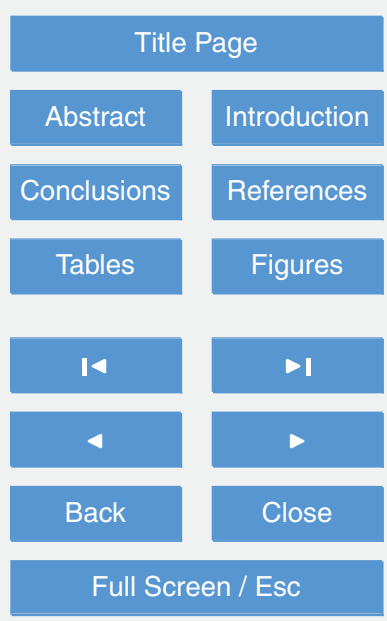

Printer-friendly Version

Interactive Discussion 
August-Roche-Magnus formula (Lawrence, 2005):

$P(T)=P_{0} \exp \left(\frac{a T}{T+b}\right)$

where

$P_{0}=6.1094 \mathrm{hPa}$

$5 \quad a=17.625$

$b=243.04$

$c=-12.75^{\circ} \mathrm{C}$

$P(T)$ is the equilibrium or saturation vapour pressure as a function of temperature $T$ on 10 the Celsius scale. The equation can be further approximated by linearizing the exponent:

$P(T)=P_{0} \exp \left(\frac{a}{b} T \frac{1}{1+\frac{T}{b}}\right)=P_{0} \exp \left(\frac{a}{b} T\left(1-\frac{1}{b} T+\ldots\right)\right) \approx P_{0} \exp \left(\gamma_{0} T\right)$,

where $\gamma_{0}=\frac{a}{b} \approx 0.073$. For values of $T$ typically ranging from -50 to $50^{\circ} \mathrm{C}$, the maximum approximation error of the final formulation is $20 \%$. Assuming snow accumulation $P s$ is itself linearly linked to the saturation vapour pressure, this justifies that within the considered temperature interval, the $P s(T)$ function can be broadly approximated with an exponential with a linear argument.

Acknowledgements. The authors thank Xavier Fettweis for providing the MARv3.2 outputs. The authors are also grateful to Aurélien Ribes for useful discussion and propositions concerning the applied statistics. We would especially like to thank Aurore Voldoire for her constant support throughout this work. We also owe our gratitude to all the others colleges who helped us at different stages of the work. This work was funded by the European Commission's 7th Framework Programme, under Grant Agreement number 226520,

Modelling the surface mass balance from

GCM output

M. Geyer et al.

Title Page

Abstract

Introduction

Conclusions

References

Tables

Figures

14

DI

4

Back

Close

Full Screen / Esc

Printer-friendly Version

Interactive Discussion

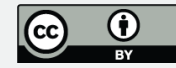


COMBINE project. The authors also acknowledge the support of Météo-France, CNRS and the French Agence Nationale de la Recherche (ANR) under reference ANR-09-CEP-001-01 (CECILE project). Figures were created using the NCL, matplotlib and CDAT graphic packages.

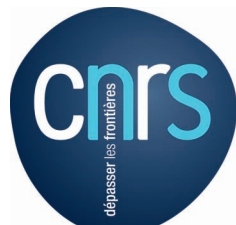

The publication of this article is financed by CNRS-INSU.

\section{References}

Amante, C. and Eakins, B. W.: ETOPO1 1 Arc-Minute Global Relief Model: Procedures, Data Sources and Analysis, NOAA Technical Memorandum NESDIS NGDC-24, 19 pp., March 2009.

10 Bamber, J. L., Griggs, J. A., Hurkmans, R. T. W. L., Dowdeswell, J. A., Gogineni, S. P., Howat, I., Mouginot, J., Paden, J., Palmer, S., Rignot, E., and Steinhage, D.: A new bed elevation dataset for Greenland, The Cryosphere, 7, 499-510, doi:10.5194/tc-7-499-2013, 2013.

Bengtsson, L., Koumoutsaris, S., and Hodges, K.: Large-scale surface mass balance of ice sheets from a comprehensive atmospheric model, Surv. Geophys., 32, 459-474, doi:10.1007/s10712-011-9120-8, 2011.

Boer, G. J.: Climate change and the regulation of the surface moisture and energy budgets, Clim. Dynam., 8, 225-239, 1993.

Bougamont, M., Bamber, J. L., Ridley, J. K., Gladstone, R. M., Greuell, W., Hanna, E., Payne, A. J., and Rutt, I.: Impact of model physics on estimating the surface mass balance of the Greenland ice sheet, Geophys. Res. Lett., 34, L17501, doi:10.1029/2007GL030700, 2007.

Box, J. E., Bromwich, D. H., and Bai, L.-S.: Greenland ice sheet surface mass balance 19912000: application of Polar MM5 mesoscale model and in situ data, J. Geophys. Res., 109, D16105, doi:10.1029/2003JD004451, 2004.
Modelling the surface mass balance from

GCM output

M. Geyer et al.

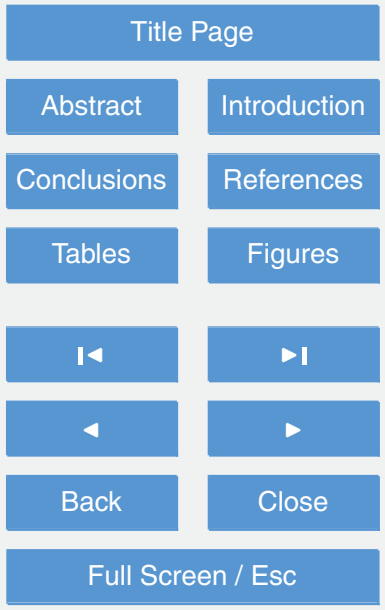

Printer-friendly Version

Interactive Discussion 
Box, J. E., Bromwich, D. H., Veenhuis, B. A., Bai, L.-S., Stroeve, J. C., Rogers, J. C., Steffen, K., Haran, T., and Wang, S.-H.:, Greenland Ice Sheet surface mass balance variability (19882004) from calibrated Polar MM5 output, J. Climate, 19, 2783-2800, 2006.

Box, J. E., Fettweis, X., Stroeve, J. C., Tedesco, M., Hall, D. K., and Steffen, K.: Greenland 5 ice sheet albedo feedback: thermodynamics and atmospheric drivers, The Cryosphere, 6, 821-839, doi:10.5194/tc-6-821-2012, 2012.

Brun, E., David, P., Sudul, M., and Brunot, G.: A numerical model to simulate snow-cover stratigraphy for operational avalanche forecasting, J. Glaciol., 38, 13-22, 1992.

Byun, K.-Y., Yang, J., and T.-Y. Lee: A snow-ratio equation and its application to numerical snowfall prediction, Weather Forecast., 23, 644-658, 2008

Cosgrove, B. A., Lohmann, D., Mitchell, K. E., Houser, P. E., Wood, E. F., Schaake, J., Robock, A., Marshall, C., Sheffield, C., Luo, L., Duan, Q., Pinker, R., T., Tarpley, J., D., Higgins, R. W., and Meng. J.: Real-time and retrospective forcing in the North American Land Data Assimilation System (NLDAS) project, J. Geophys. Res., 108, 8842, doi:10.1029/2002JD003118, 2003.

Dee, D. P., Uppala, S. M., Simmons, A. J., Berrisford, P., Poli, P., Kobayashi, S., Andrae, U., Balmaseda, M. A., Balsamo, G., Bauer, P., Bechtold, P., Beljaars, A. C. M., van de Berg, L., Bidlot, J., Bormann, N., Delsol, C., Dragani, R., Fuentes, M., Geer, A. J., Haimberger, L., Healy, S. B., Hersbach, H., Hólm, E. V., Isaksen, L., Kållberg, P., Köhler, M., Matricardi, M., McNally, A. P., Monge-Sanz, B. M., Morcrette, J.-J., Park, B.-K., Peubey, C., de Rosnay, P., Tavolato, C., Thépaut, J.-N., and Vitart, F.: The ERA-Interim reanalysis: configuration and performance of the data assimilation system, Q. J. Roy. Meteorol. Soc., 137, 553-597, doi:10.1002/qj.828, 2011.

Derksen, C. and Brown, R.: Spring snow cover extent reductions in the 20082012 period exceeding climate model projections, Geophys. Res. Lett., 39, L19504, doi:10.1029/2012GL053387, 2012.

Ettema, J., van den Broeke, M. R., van Meijgaard, E., van de Berg, W. J., Bamber, J. L., Box, J. E., and Bales, R. C.: Higher surface mass balance of the Greenland ice sheet revealed by high-resolution climate modelling, Geophys. Res. Lett., 36, L12501, doi:10.1029/2009GL038110, 2009.

Fausto, R. S., Ahlstrøm, A. P., van As, D., Bøggild, C. E., and Johnsen, S. J.: A new present-day temperature parameterization for Greenland, J. Glaciol., 55, 95-105, doi:10.3189/002214309788608985, 2009.

\section{TCD}

7, 3163-3207, 2013

Modelling the surface mass balance from

GCM output

M. Geyer et al.

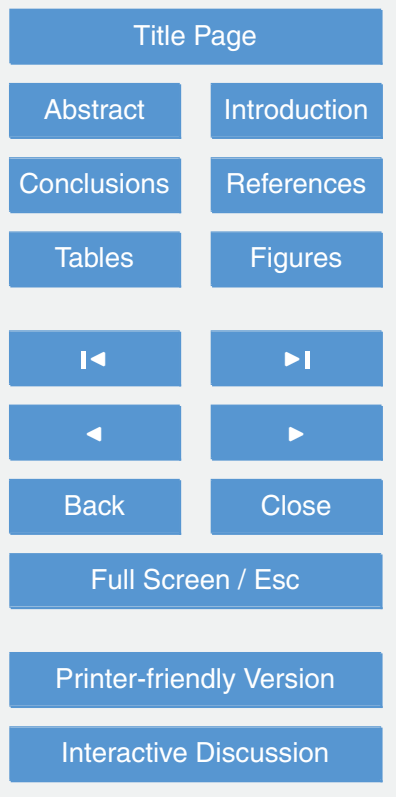


Fettweis, X., Hanna, E., Gallée, H., Huybrechts, P., and Erpicum, M.: Estimation of the Greenland ice sheet surface mass balance for the 20th and 21st centuries, The Cryosphere, 2, 117-129, doi:10.5194/tc-2-117-2008, 2008.

Fettweis, X., Tedesco, M., van den Broeke, M., and Ettema, J.: Melting trends over the Green5 land ice sheet (1958-2009) from spaceborne microwave data and regional climate models, The Cryosphere, 5, 359-375, doi:10.5194/tc-5-359-2011, 2011.

Fettweis, X., Franco, B., Tedesco, M., van Angelen, J. H., Lenaerts, J. T. M., van den Broeke, M. R., and Gallée, H.: Estimating Greenland ice sheet surface mass balance contribution to future sea level rise using the regional atmospheric climate model MAR, The

10 Cryosphere Discuss., 6, 3101-3147, doi:10.5194/tcd-6-3101-2012, 2012.

Franco, B., Fettweis, X., and Erpicum, M.: Future projections of the Greenland ice sheet energy balance driving the surface melt, The Cryosphere, 7, 1-18, doi:10.5194/tc-7-1-2013, 2013.

Gallée, H., Agosta, C., Gential, L., Favier, V., and Krinner, G.: A downscaling approach towards high-resolution surface mass balance over Antarctica, Surv. Geophys., 32, 507-518, 15 doi:10.1007/s10712-011-9125-3, 2011.

Gregory, J. M. and Huybrechts, P.: Ice-sheet contributions to future sea-level change, Philos. T. R. Soc. A, 364, 1709-1732, doi:10.1098/rsta.2006.1796, 2006.

Hanna, E., Huybrechts, P., Steffen, K., Cappelen, J., Huff, R., Shuman, C., Irvine-Fynn, T., Wise, S., and Griffiths, M.: Increased runoff from melt from the Greenland Ice Sheet: a response to global warming, J. Climate, 21, 331-341, 2008.

Helsen, M. M., van de Wal, R. S. W., van den Broeke, M. R., van de Berg, W. J., and Oerlemans, J.: Coupling of climate models and ice sheet models by surface mass balance gradients: application to the Greenland Ice Sheet, The Cryosphere, 6, 255-272, doi:10.5194/tc6-255-2012, 2012.

Huybrechts, P., Gregory, J., Janssens, I., and Wild, M.: Modelling Antarctic and Greenland volume changes during the 20th and 21st centuries forced by GCM time slice integrations, Global Planet. Change, 42, 83-105, 2004.

Krinner, G. and Julien, N.: High-resolution simulations of the surface mass balance of Greenland at the end of this century, The Cryosphere Discuss., 1, 351-383, doi:10.5194/tcd-1-3512007, 2007.

Lawrence, M. G.: The relationship between relative humidity and the dew point temperature in moist air: a simple conversion and applications, B. Am. Meteorol. Soc., 86, 225-233, 2005.
Modelling the surface mass balance from

GCM output

M. Geyer et al.

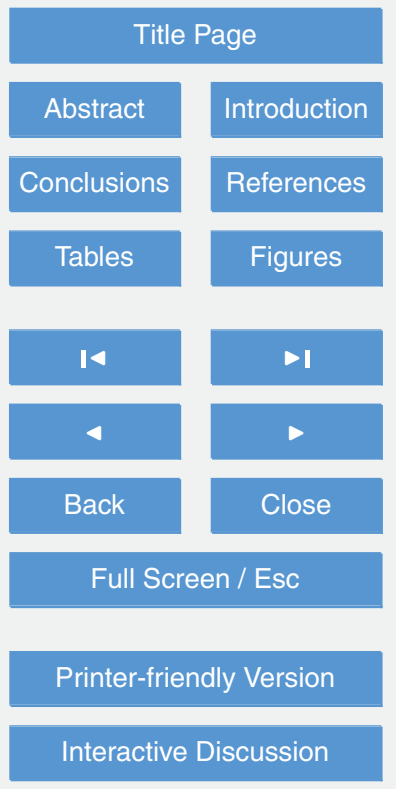


Lucas-Picher, P., Wulff-Nielsen, M., Christensen, J. H., Aðalgeirsdóttir, G., Mottram, R., and Simonsen, S. B.: Very high resolution regional climate model simulations over Greenland identifying added value, J. Geophys. Res., 117, D02108, doi:10.1029/2011JD016267, 2011.

Lefebre, F., Gallée, H., van Ypersele., J.-P., and Greuell, W.: Modeling of snow and ice melt at 5 ETH Camp (West Greenland): a study of surface albedo, J. Geophys. Res., 108, D84231, doi:10.1029/2001JD001160, 2003.

Meehl, G. A., Collins, W. D., Friedlingstein, P., Gaye, A. T., Gregory, J. M., Kitoh, A., Knutti, R., Murphy, J. M., Noda, A., Raper, S. C. B., Watterson, I. G., Weaver, A. J., and Zhao, Z.-C.: Global climate projections, in: Climate Change 2007: The Physical Science Basis. Contribution of Working Group I to the Fourth Assessment Report of the Intergovernmental Panel on Climate Change, edited by: Solomon, S., Qin, D., Manning, M., Chen, Z., Marquis, M., Avery, K. B., Tingor, M., and Miller, H. L., Cambridge University Press, Cambridge, United Kingdom and New York, NY, USA, 2007.

Nghiem, S. V., Hall, D. K., Mote, T. L., Tedesco, M., Albert, M. R., Keegan, K., Shuman, C. A., 15 DiGirolamo, N. E., and Neuman, G.: The extreme melt across the Greenland ice sheet in 2012, Geophys. Res. Lett., 39, L20502, doi:10.1029/2012GL053611, 2012.

Oerlemans, J., Bassford, R. P., Chapman, W., Dowdeswell, J. A., Glazovsky, A. F., Hagen, J. O., Melvold, K., de Wildt, M. R., and van de Wal, R. S. W.: Estimating the contribution from Arctic glaciers to sea-level change in the next hundred years, Ann. Glaciol., 42, 230-236, 2005.

Quiquet, A., Punge, H. J., Ritz, C., Fettweis, X., Gallée, H., Kageyama, M., Krinner, G., Salas y Mélia, D., and Sjolte, J.: Sensitivity of a Greenland ice sheet model to atmospheric forcing fields, The Cryosphere, 6, 999-1018, doi:10.5194/tc-6-999-2012, 2012.

Rae, J. G. L., Aðalgeirsdóttir, G., Edwards, T. L., Fettweis, X., Gregory, J. M., Hewitt, H. T., Lowe, J. A., Lucas-Picher, P., Mottram, R. H., Payne, A. J., Ridley, J. K., Shannon, S. R., van de Berg, W. J., van de Wal, R. S. W., and van den Broeke, M. R.: Greenland ice sheet surface mass balance: evaluating simulations and making projections with regional climate models, The Cryosphere, 6, 1275-1294, doi:10.5194/tc-6-1275-2012, 2012.

Reeh, N.: Parameterization of melt rate and surface temperature on the Greenland Ice Sheet, Polarforschung, 59, 113-128, 1991.

so Rignot, E., Velicogna, I., van den Broeke, M. R., Monaghan, A., and Lenaerts, J.: Acceleration of the contribution of the Greenland and Antarctic ice sheets to sea level rise, Geophys. Res. Lett., 38, L05503, doi:10.1029/2011GL046583, 2011.
Modelling the surface mass balance from GCM output

M. Geyer et al.

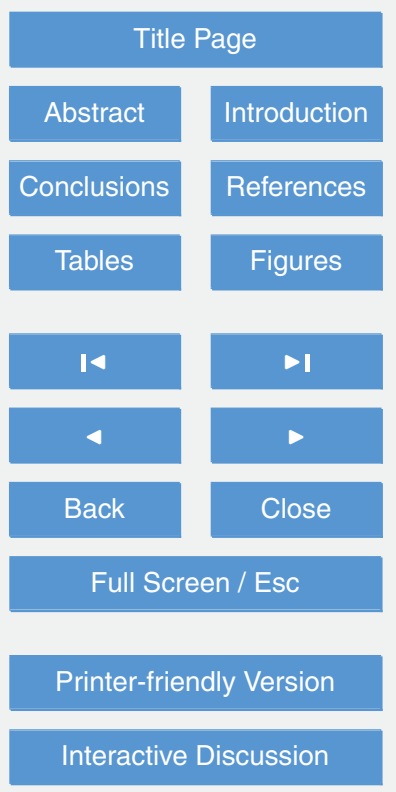


Sørensen, L. S., Simonsen, S. B., Nielsen, K., Lucas-Picher, P., Spada, G., Adalgeirsdottir, G., Forsberg, R., and Hvidberg, C. S.: Mass balance of the Greenland ice sheet (2003-2008) from ICESat data - the impact of interpolation, sampling and firn density, The Cryosphere, 5, 173-186, doi:10.5194/tc-5-173-2011, 2011.

5 Stroeve, J., Box, J. E., Gao, F., Liang, S., Nolin, A., and Schaaf, C.: Accuracy assessment of the MODIS 16-day albedo product for snow: comparisons with Greenland in situ measurements, Remote Sens. Environ., 94, 46-60, doi:10.1016/j.rse.2004.09.001, 2005.

Stroeve, J. C., Kattsov, V., Barrett, A. P., Serreze, M. C., Pavlova, T., Holland, M. M., and Meier, W. N.: Trends in Arctic sea ice extent from CMIP5, CMIP3 and observations, Geophys. Res. Lett., 39, L16502, doi:10.1029/2012GL052676, 2012.

Tarasov, L. and Peltier, W. R.: Greenland glacial history and local geodynamic consequences, Geophys. J. Int., 150, 198-229, doi:10.1046/j.1365-246X.2002.01702.x, 2002.

Tedesco, M., Fettweis, X., van den Broeke, M. R., van de Wal, R. S., W., Smeets, C. J. P. P., van de Berg, W. J., Serreze, M. C., and Box, J. E.: The role of albedo and accumulation in the 2010 melting record in Greenland, Environ. Res. Lett., 6, 014005, doi:10.1088/17489326/6/1/014005, 2011.

Tedesco, M., Fettweis, X., Mote, T., Wahr, J., Alexander, P., Box, J., and Wouters, B.: Evidence and analysis of 2012 Greenland records from spaceborne observations, a regional climate model and reanalysis data, The Cryosphere Discuss., 6, 4939-4976, doi:10.5194/tcd-64939-2012, 2012.

Valcke, S.: The OASIS3 coupler: a European climate modelling community software, Geosci. Model Dev., 6, 373-388, doi:10.5194/gmd-6-373-2013, 2013.

van de Wal, R. S. W., Boot, W., Smeets, C. J. P. P., Snellen, H., van den Broeke, M. R., and Oerlemans, J.: Twenty-one years of mass balance observations along the K-transect, West Greenland, Earth Syst. Sci. Data, 4, 31-35, doi:10.5194/essd-4-31-2012, 2012.

Vionnet, V., Brun, E., Morin, S., Boone, A., Faroux, S., Le Moigne, P., Martin, E., and Willemet, J.-M.: The detailed snowpack scheme Crocus and its implementation in SURFEX v7.2, Geosci. Model Dev., 5, 773-791, doi:10.5194/gmd-5-773-2012, 2012.

Vizcaíno, M., Mikolajweicz, U., Jungclaus, J., and Schurgers, G.: Climate modification by future ice sheet changes and consequences for ice sheet mass balance, Clim. Dynam., 34, 301324, 2010.

Voldoire, A., Sanchez-Gomez, E., Salas y Melia, D., Decharme, B., Cassou, C., Senesi, S., Valcke, S., Beau, I., Alias, A., Chevallier, M., Deque, M., Deshayes, J., Douville, H., Fernan-
Modelling the surface mass balance from

GCM output

M. Geyer et al.

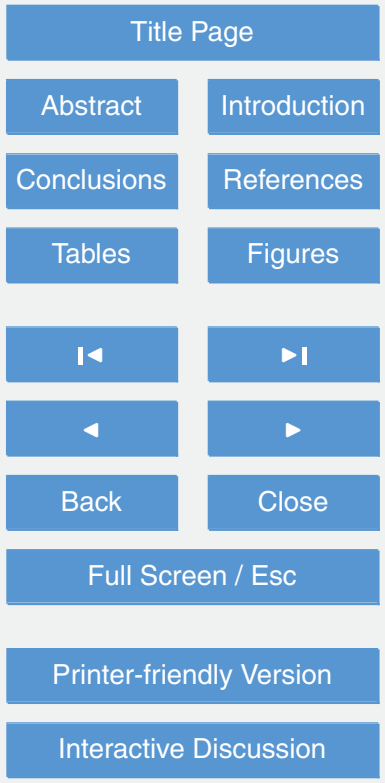


dez, E., Madec, G., Maisonnave, E., Moine, M.-P., Planton, S., Saint-Martin, D., Szopa, S., Tyteca, S., Alkama, R., Belamari, S., Braun, A., Coquart, L., and Chauvin, F.: The CNRMCM5.1 global climate model: description and basic evaluation, Clim. Dynam., 40, 2091-2121, doi:10.1007/s00382-011-1259-y, 2013.

5 Wake, L. M., Huybrechts, P., Box, J. E., Hanna, E., Janssens, I., Milne, G. A.: Surface massbalance changes of the Greenland ice sheet since 1866, Ann. Glaciol., 50, 178-184, 2009.

Modelling the surface mass balance from

GCM output

M. Geyer et al.

Title Page

Full Screen / Esc 

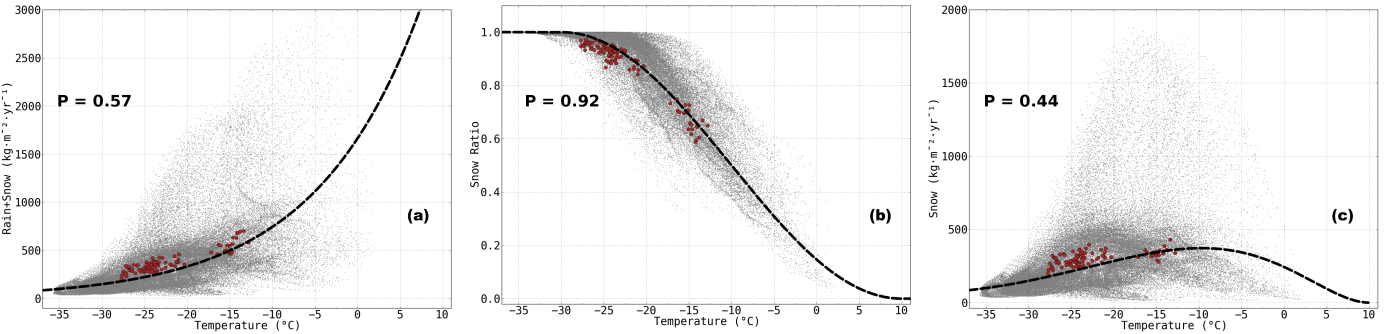

Modelling the surface mass balance from

GCM output

M. Geyer et al.

Fig. 1. (a) $10 \mathrm{yr}$ mean precipitation rate $\left(\mathrm{kg} \mathrm{m}^{-2} \mathrm{yr}^{-1}\right)$ modelled by Crocus (forced by CNRMCM5.1 atmospheric outputs) against near-surface air temperature in ${ }^{\circ} \mathrm{C}$ (grey dots). Each dot corresponds to a grid point of the GrIS. The dashed line is a RMS exponential fit of these data and $P$ is the corresponding Pearson correlation coefficient. The annual data averaged over the entire GrIS are represented as brown dots. (b) Same as (a), but for snow-ratio (snow precipitation over total precipitation). The dashed line is a RMS co-sinusoidal fit of these data. (c) Same as (b), but for solid precipitation rate. The dashed line is the product of the two previous fits.

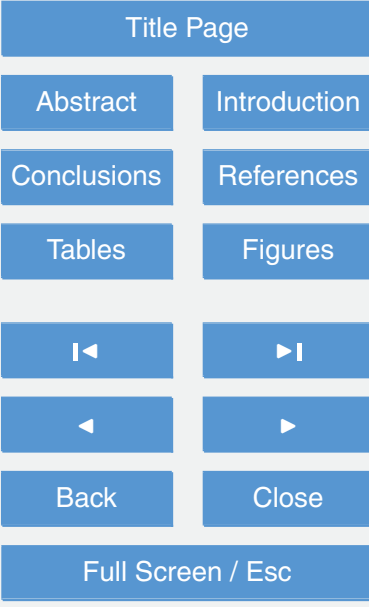

Printer-friendly Version

Interactive Discussion 


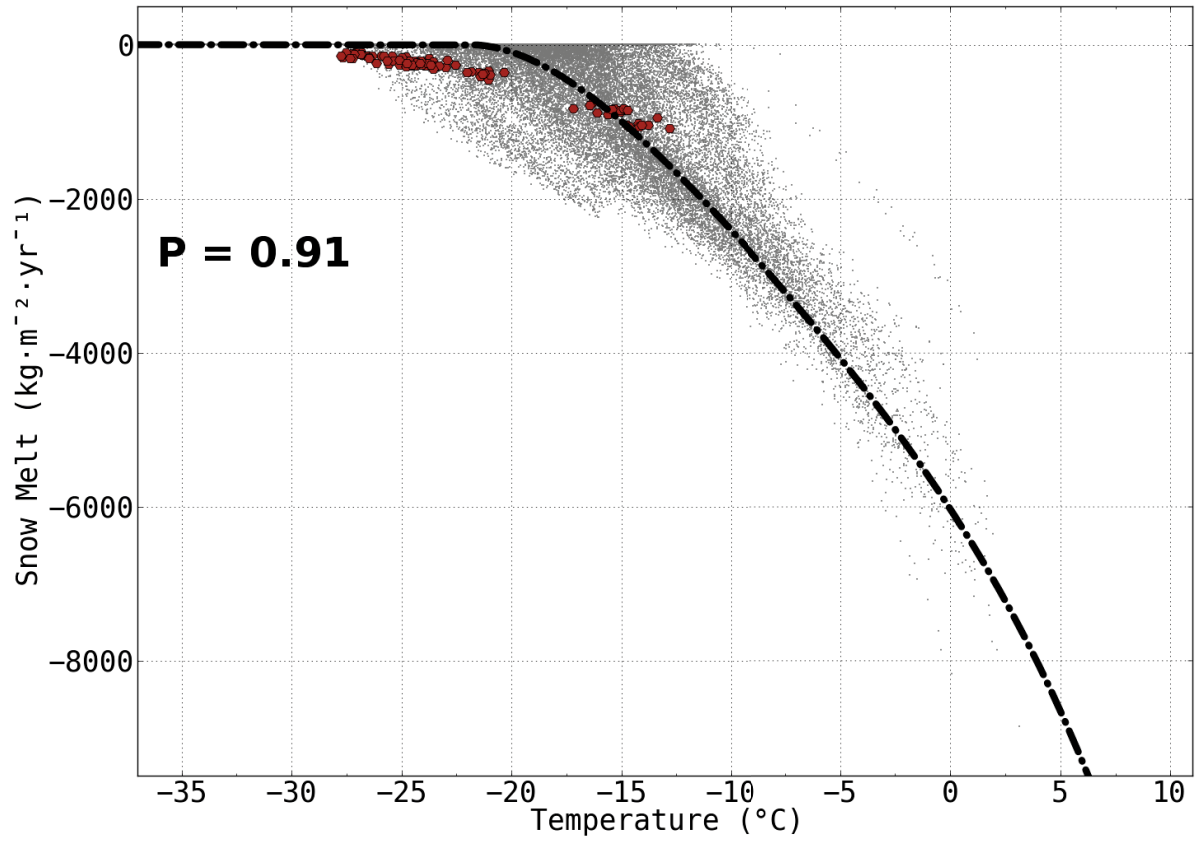

Fig. 2. $10 \mathrm{yr}$ mean snowmelt $\left(\mathrm{kgm}^{-2} \mathrm{yr}^{-1}\right)$ modelled by Crocus (forced by CNRM-CM5.1 atmospheric outputs) against near-surface air temperature in ${ }^{\circ} \mathrm{C}$ (grey dots). Each dot corresponds to a grid point of the GrIS. The dashed-dotted line is a RMS polynomial fit of these data and $P$ is the corresponding Pearson correlation coefficient. The annual data averaged over the entire GrIS are represented as brown dots.
TCD

7, 3163-3207, 2013

Modelling the surface mass balance from

GCM output

M. Geyer et al.

Title Page
Abstract

Conclusions

Tables

14

4

Back 


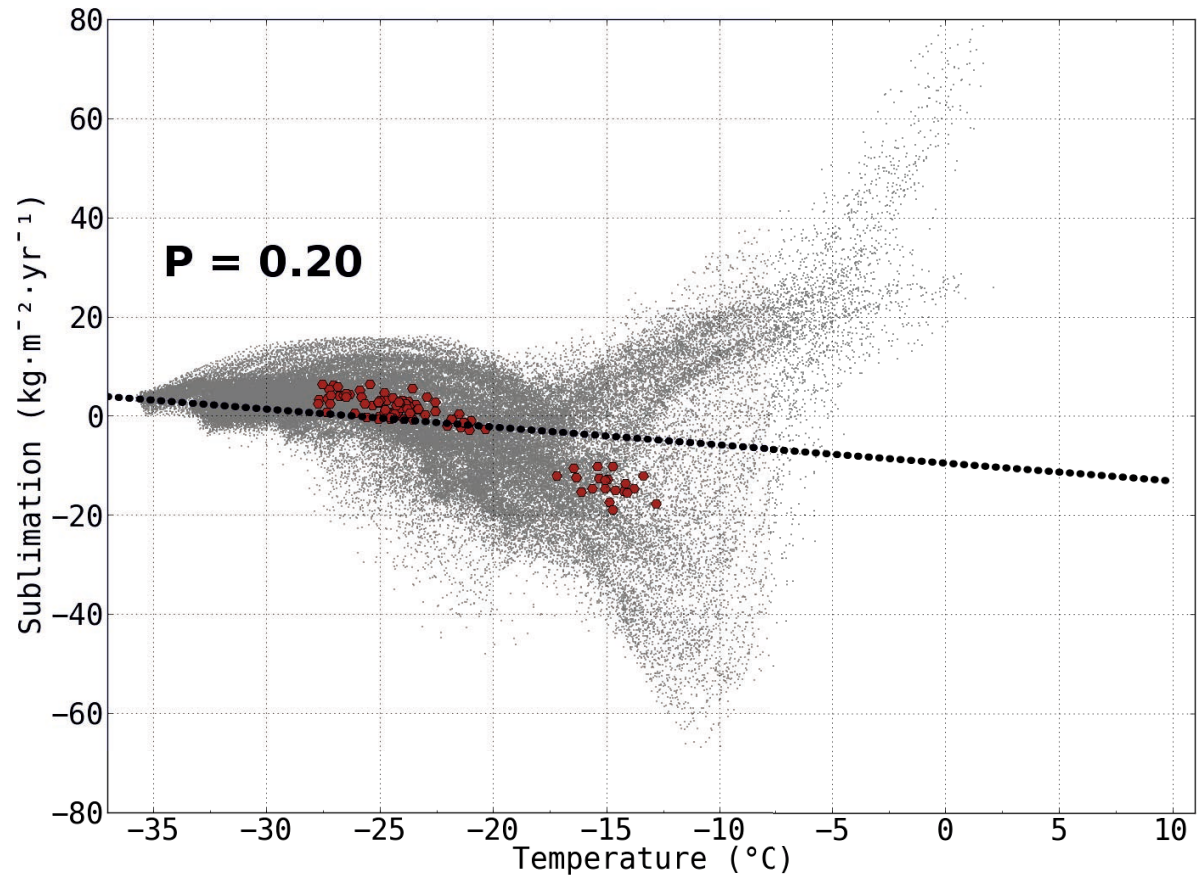

7, 3163-3207, 2013

Modelling the surface mass balance from

GCM output

M. Geyer et al.

Title Page

Abstract

Conclusions

Tables

14

4

Back
Introduction

References

Figures

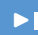

$>$

Close

Fig. 3. $10 \mathrm{yr}$ mean sublimation rate $\left(\mathrm{kg} \mathrm{m}^{-2} \mathrm{yr}^{-1}\right)$ modelled by Crocus (forced by CNRM-CM5.1 atmospheric outputs) against near-surface air temperature in ${ }^{\circ} \mathrm{C}$ (grey dots). Each dot corresponds to a grid point of the GrIS. The dotted line is a RMS linear fit of these data and $P$ is the corresponding Pearson correlation coefficient. The annual data averaged over the entire GrIS are represented as brown dots.

Printer-friendly Version

Interactive Discussion 


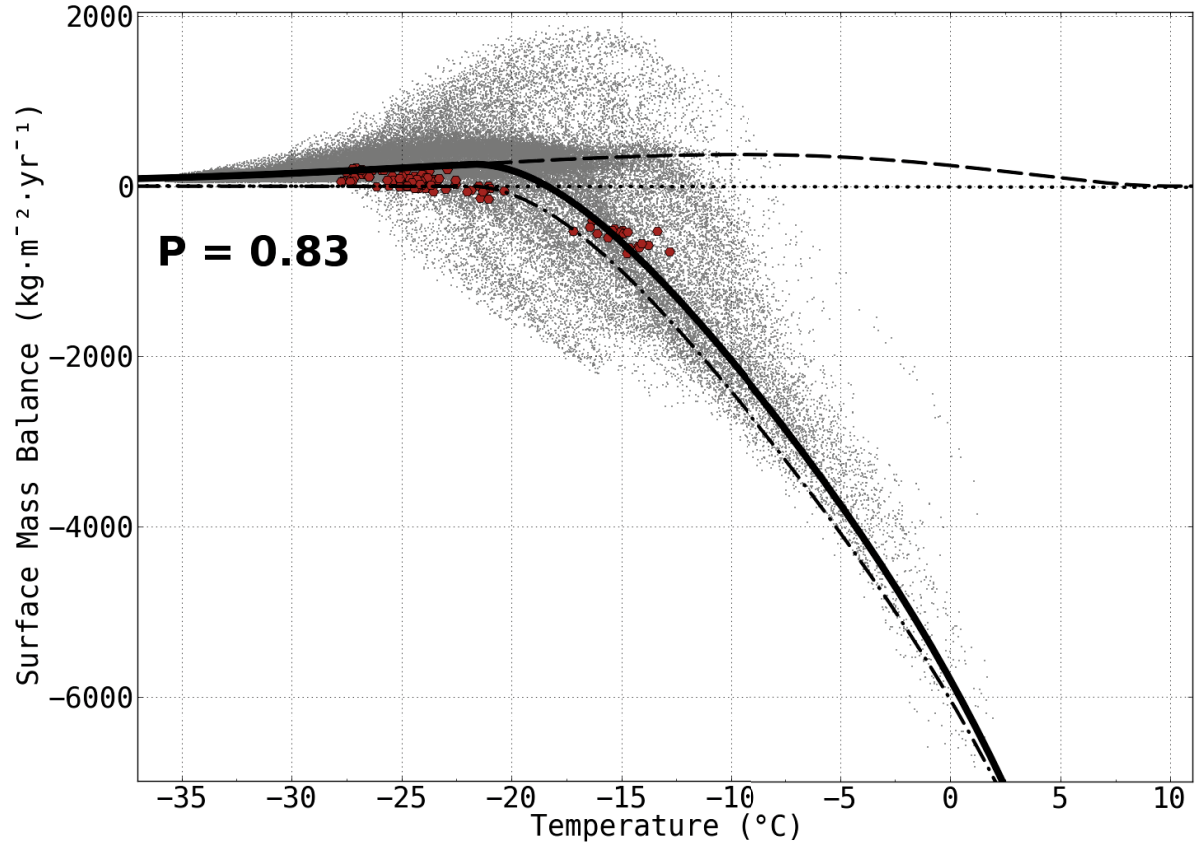

Fig. 4. $10 \mathrm{yr}$ mean surface mass balance $\left(\mathrm{kgm}^{-2} \mathrm{yr}^{-1}\right)$ modelled by Crocus (forced by CNRMCM5.1 atmospheric outputs) against near-surface air temperature in ${ }^{\circ} \mathrm{C}$ (grey dots). Each dot corresponds to a grid point of the GrIS. The dashed, dash-dotted and dotted lines are respectively the fits for the solid precipitation rate, snowmelt and sublimation. The solid line is the sum of the previous three. $P$ is the Pearson correlation between the obtained function and the data. The annual data averaged over the entire GrIS are represented as brown dots.
TCD

7, 3163-3207, 2013

Modelling the surface mass balance from

GCM output

M. Geyer et al.

Title Page

Abstract

Introduction

Conclusions

References

Tables

Figures

14

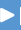

4

Back

Close

Full Screen / Esc

Printer-friendly Version

Interactive Discussion 


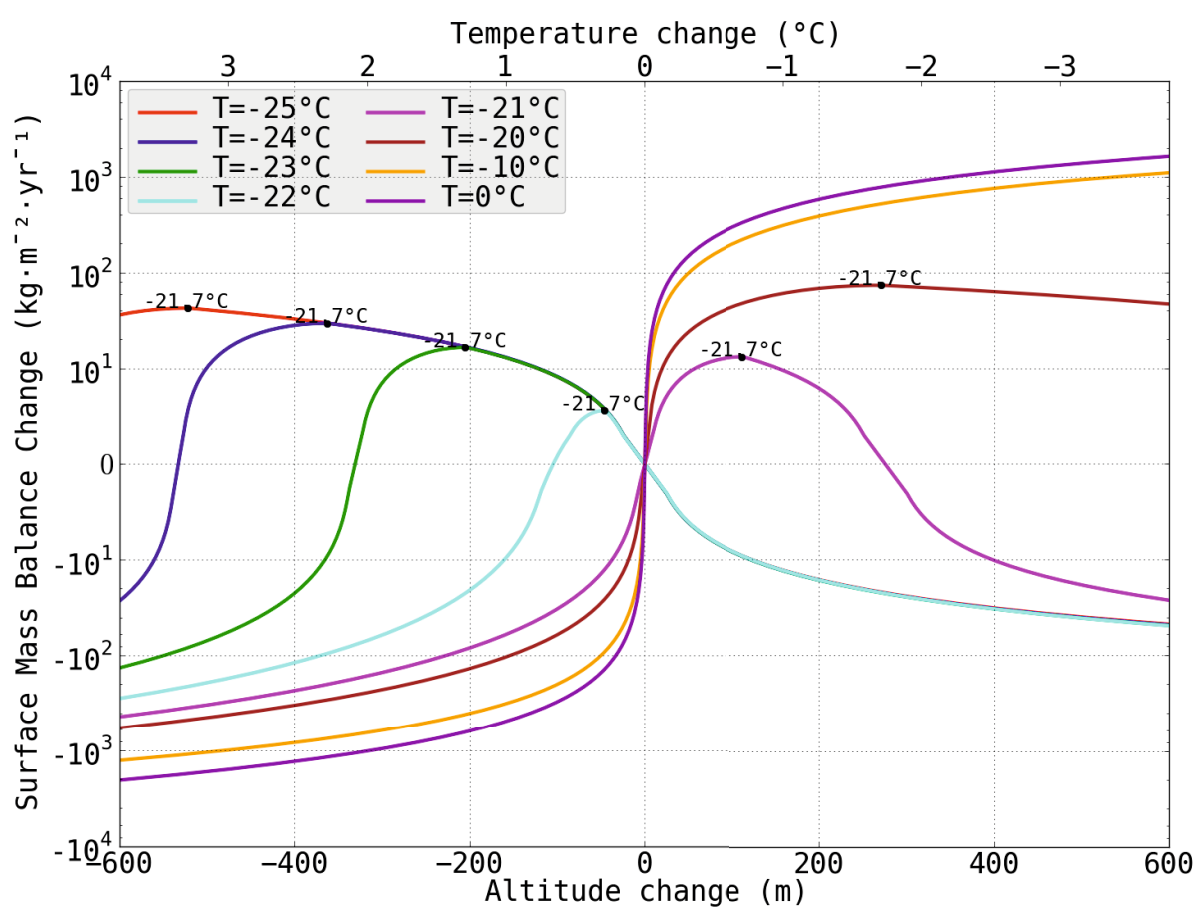

Fig. 5. Surface mass balance changes $\left(\mathrm{kg} \mathrm{m}^{-2} \mathrm{yr}^{-1}\right)$ against altitude variations (lower x-axis, in $\mathrm{m}$ ) and the equivalent temperature variations assuming a constant lapse rate (upper $\mathrm{x}$-axis, in ${ }^{\circ} \mathrm{C}$ ). The different curves correspond to different near-surface air temperatures without any altitude change $(\Delta H=0)$. Black solid points mark the temperature at which the SMB function $B$ reaches its maximum.
TCD

7, 3163-3207, 2013

Modelling the surface mass balance from

GCM output

M. Geyer et al.

Title Page

Abstract

Introduction

Conclusions

References

Tables

Figures

14

$>1$

Back

Close

Full Screen / Esc

Printer-friendly Version

Interactive Discussion 

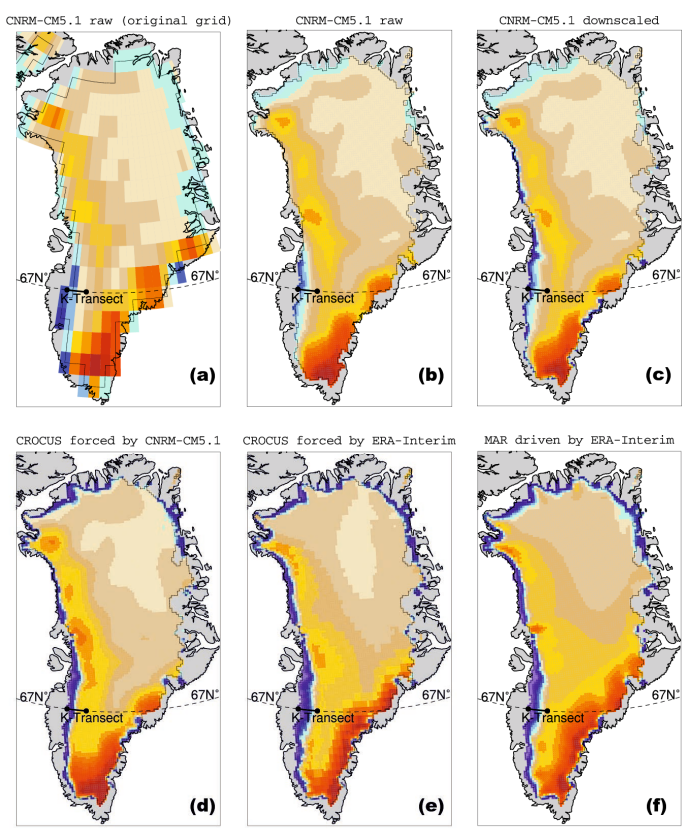

$\begin{array}{lrrrrrrrrrr}-2 & -1.8 & -1.6 & -1.4 & -1.2 & -1 & -0.8 & -0.6 & -0.4 & -0.2 & 0 \\ \text { m/yr in w.e. } & 0.2 & 0.4 & 0.6 & 0.8 & 1 & 1.2 & 1.4\end{array}$

Fig. 6. (a) Annual mean 1989-2008 raw surface mass balance ( $\mathrm{yr}^{-1}$ in water equivalent) modelled by CNRM-CM5.1 on the original $150 \mathrm{~km}$ grid. For 2006-2008 the RCP8.5 climate scenario is considered. The K-transect is represented as the solid, bold segment. (b) Same as (a), but for CNRM-CM5.1 SMB bilinearly interpolated from $150 \mathrm{~km}$ to $15 \mathrm{~km}$-resolution. (c) Same as (a), but for downscaled CNRM-CM5.1 SMB. (d) Same as (a), but the SMB modelled by Crocus forced by CNRM-CM5.1 atmospheric outputs. (e) Same as (d), but for Crocus forced by ERA-Interim. (f) Same as (e), but for RCM MAR driven by ERA-Interim lateral boundary conditions.
TCD

7, 3163-3207, 2013

Modelling the surface mass balance from

GCM output

M. Geyer et al.

Title Page

Abstract

Introduction

Conclusions

References

Tables

Figures

14

$>1$

4

Back

Close

\section{Full Screen / Esc}

Printer-friendly Version

Interactive Discussion 


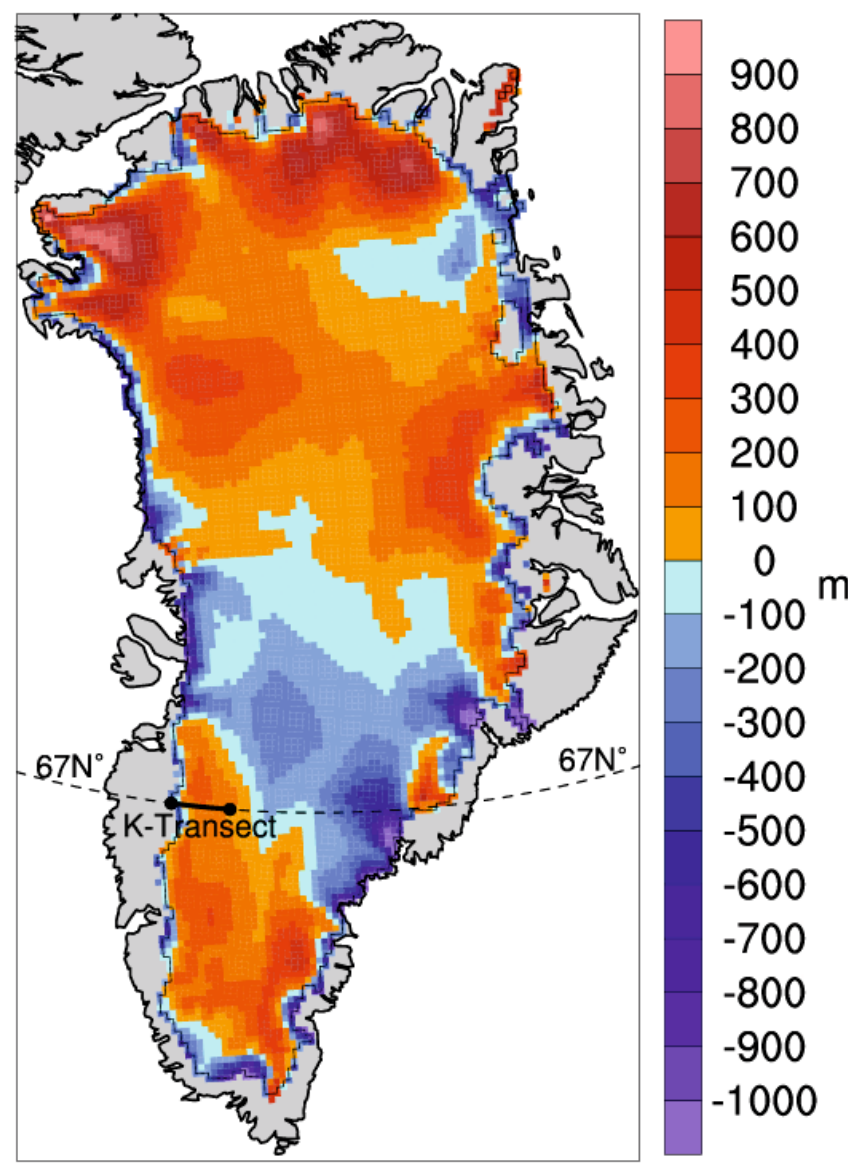

Fig. 7. The CNRM-CM5.1 topography, interpolated from $150 \mathrm{~km}$ to $15 \mathrm{~km}$, minus the ETOPO1 topography of the GrIS (in m).

\section{TCD}

7, 3163-3207, 2013

Modelling the surface mass balance from

GCM output

M. Geyer et al.

Title Page

Abstract

Introduction

Conclusions

References

Tables

Figures

14

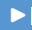

4

Back

Close 

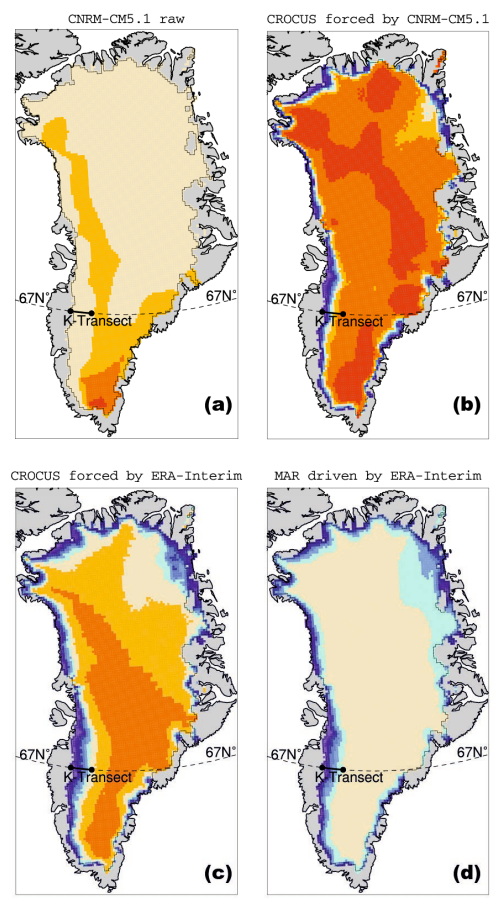

$\begin{array}{lllllllllll}0.73 & 0.74 & 0.75 & 0.76 & 0.77 & 0.78 & 0.79 & 0.8 & 0.81 & 0.82 & 0.83\end{array}$

Fig. 8. (a) Annual mean 1989-2008 albedo (interval range [0-1]) of raw CNRM-CM5.1 interpolated from $150 \mathrm{~km}$ to $15 \mathrm{~km}$-resolution. For 2006-2008 the RCP8.5 climate scenario is considered. The K-transect is represented as the solid, bold segment. (b) Same as (a), but for Crocus forced by CNRM-CM5.1 atmospheric outputs. (c) Same as (b), but for Crocus forced by ERA-Interim. (d) Same as (c), but for RCM MAR driven by ERA-Interim lateral boundary conditions.
TCD

\section{7, 3163-3207, 2013}

Modelling the surface mass balance from

GCM output

M. Geyer et al.

\section{Title Page}

Abstract

Introduction

Conclusions

References

Tables

Figures

14

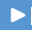

Back

Close

Full Screen / Esc

Printer-friendly Version

Interactive Discussion 

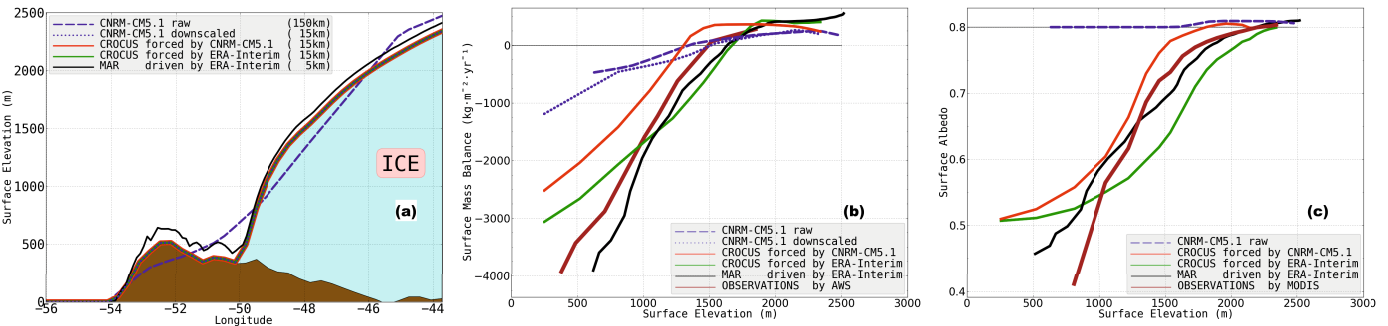

Modelling the surface mass balance from

GCM output

M. Geyer et al.

Fig. 9. (a) Cross-section of the GrlS along the K-transect $\left(67^{\circ} \mathrm{N}\right)$ for CNRM-CM5.1, ETOPO1 and MAR topographies (in ma.s.l.). Cross-sections are averaged in the band [66.5 $\left.5^{\circ} \mathrm{N}-67.5^{\circ} \mathrm{N}\right]$. For RCM MAR case, the original $5 \times 5 \mathrm{~km}^{2}$ grid data are used. (b) Same as (a), but for annual mean 2000-2010 surface mass balance $\left(\mathrm{kg} \mathrm{m}^{-2} \mathrm{yr}^{-1}\right)$. For 2006-2010, the RCP8.5 scenario is considered. Dashed and dotted blue lines correspond respectively to the raw and to the downscaled CNRM-CM5.1 simulations, red and green solid lines correspond respectively to Crocus simulations forced by CNRM-CM5.1 atmospheric outputs and ERA-Interim, black line corresponds to RCM MAR simulations driven by ERA-Interim lateral boundary conditions and brown lines correspond to the AWS observations. (c) Same as (b), but for summer surface albedo; black line corresponds to MODIS observations.

Title Page

4

\section{Full Screen / Esc}

Printer-friendly Version

Interactive Discussion 


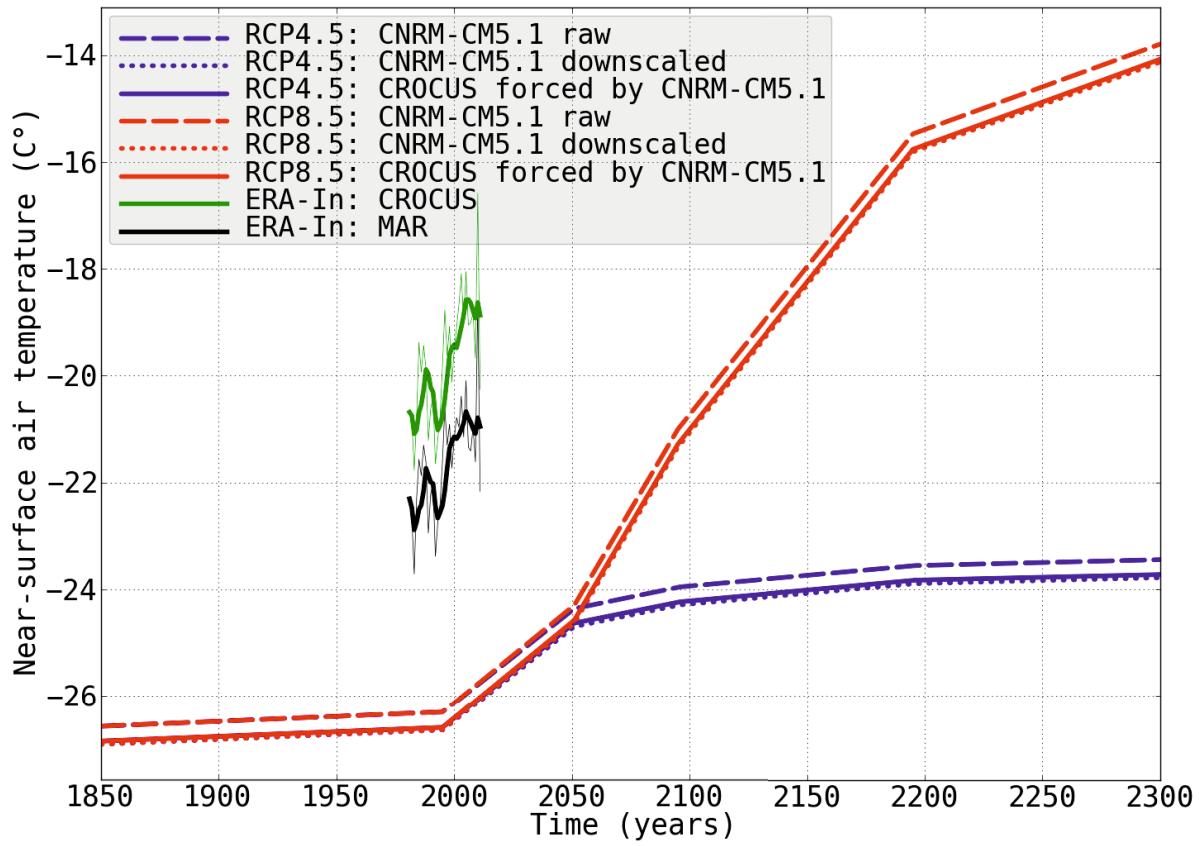

Fig. 10. Annual near-surface air temperature $\left({ }^{\circ} \mathrm{C}\right)$ averaged over the entire GrlS. Blue and red lines correspond to RCP4.5 and RCP8.5 future climate scenarios, respectively, green and black lines (thin: annual mean data, bold: $5 \mathrm{yr}$ running mean) correspond to ERA-Interim forcings passed to Crocus and RCM MAR. Dashed and dotted lines correspond to the raw and downscaled temperature of CNRM-CM5.1 simulations, respectively, and solid lines represent Crocus simulations. For all the output based on CNRM-CM5.1 data, time-interpolation is applied between the snapshots averaged by $10 \mathrm{yr}$ chunks (centred in 1850, 1995, 2050, 2095, $2195,2295)$ in order to generate continuous data over the entire $1850-2300$ time period.
TCD

7, 3163-3207, 2013

Modelling the surface mass balance from

GCM output

M. Geyer et al.

Title Page

Abstract

Introduction

Conclusions

References

Tables

Figures

14

$>1$

4

Back

Close

Full Screen / Esc

Printer-friendly Version

Interactive Discussion 

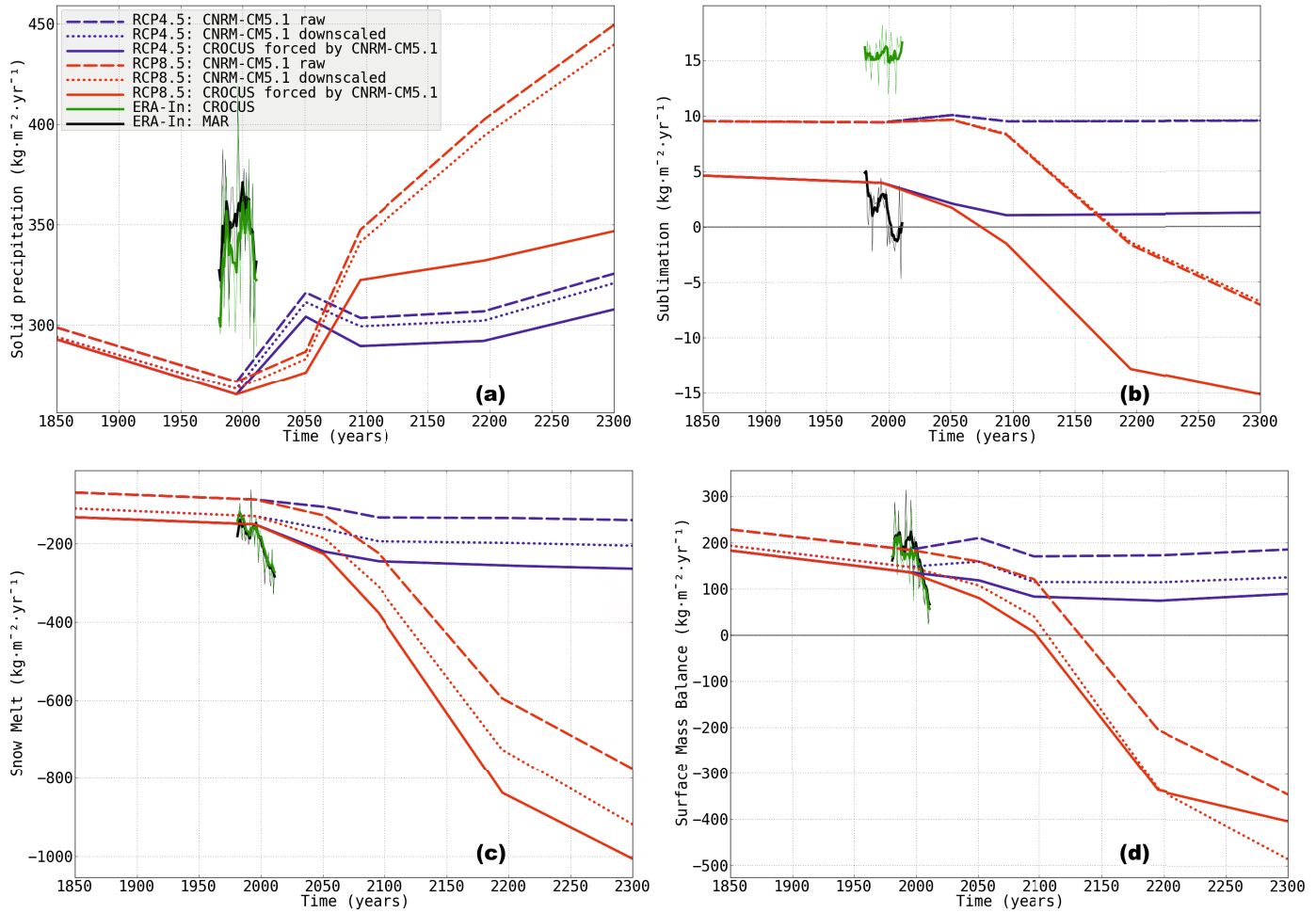

Fig. 11. Same as Fig. 10, but (a) for the annual mean solid precipitation $\left(\mathrm{kg} \mathrm{m}^{-2} \mathrm{yr}^{-1}\right)$, (b) sublimation, (c) snowmelt and (d) surface mass balance.
TCD

7, 3163-3207, 2013

Modelling the surface mass balance from

GCM output

M. Geyer et al.

\section{Title Page}

4

Back

\section{Close}

\section{Full Screen / Esc}

Printer-friendly Version

Interactive Discussion 

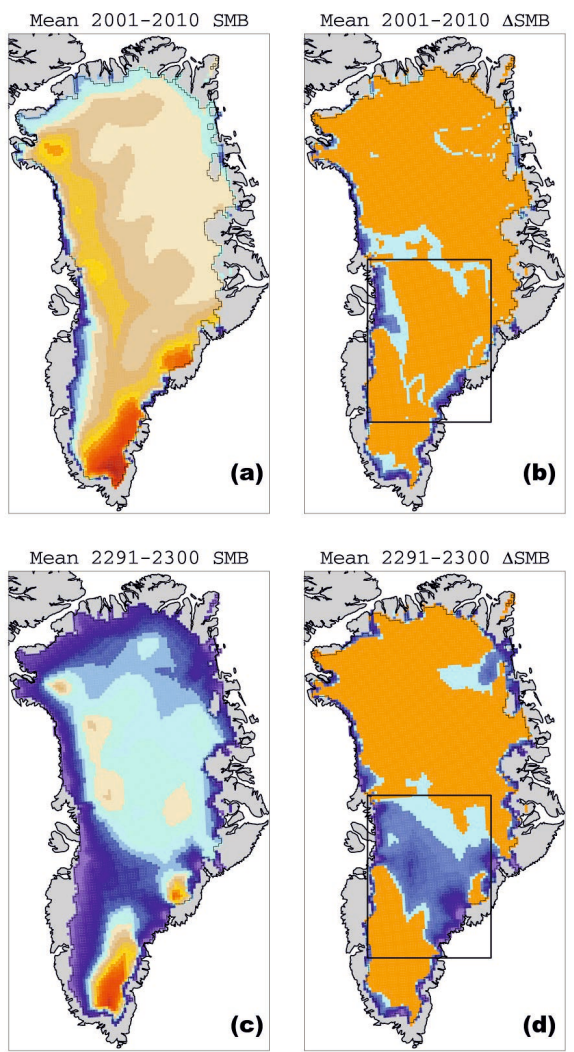

$-1.5-1.4-1.3-1.2-1.1-1 \quad-0.9-0.8-0.7-0.6-0.5-0.4-0.3-0.2-0.100 .1$

Fig. 12. (a) Annual mean 2001-2010 CNRM-CM5.1 surface mass balance $\mathrm{myr}^{-1}$ in water equivalent) downscaled from $150 \mathrm{~km}$ to $15 \mathrm{~km}$-resolution. For 2006-2010 the RCP8.5 scenario is considered. (b) Difference (a) minus the corresponding raw CNRM-CM5.1 SMB for 20012010. (c) and (d) Same as respectively (a) and (b), but for 2291-2300.
TCD

\section{7, 3163-3207, 2013}

Modelling the surface mass balance from

GCM output

M. Geyer et al.

Title Page

Abstract

Introduction

Conclusions

References

Tables

Figures

14

$D$

4

Back

Close

Full Screen / Esc

Printer-friendly Version

Interactive Discussion 

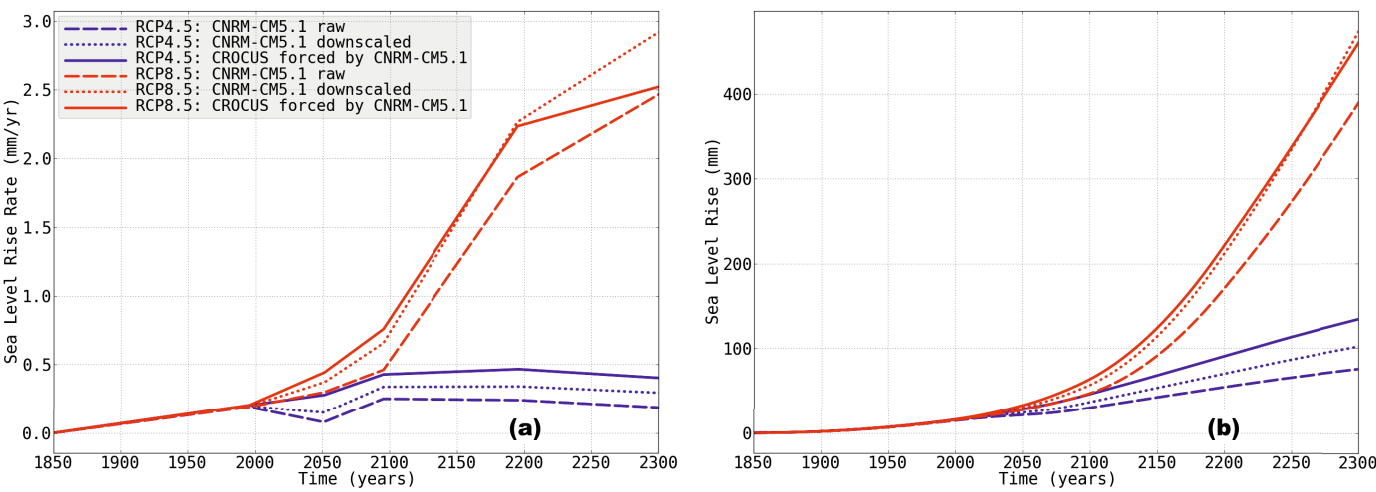

Fig. 13. (a) The rate of total GrIS SMB change from the end of the pre-industrial era (1850) expressed in global sea level rise rate equivalent $\left(\mathrm{mmyr}^{-1}\right)$. Blue and red lines correspond to RCP4.5 and RCP8.5 future climate scenarios, respectively. Dashed and dotted lines correspond to the raw and downscaled CNRM-CM5.1 simulations, respectively; solid lines correspond to Crocus simulations. For output based on CNRM-CM5.1 data, time-interpolation is applied between the averaged snapshots (centred in 1850, 1995, 2050, 2095, 2195, 2295) in order to generate continuous data over the entire 1850-2300 time period. (b) Same as (a), but for the cumulative total GrIS SMB change from the end of the pre-industrial era (1850) expressed in absolute sea level rise equivalent $(\mathrm{mm})$.
Modelling the surface mass balance from

GCM output

M. Geyer et al.

Title Page

Abstract

Introduction

Conclusions

References

Tables

Figures

14

$>1$

4

Back

Close

Full Screen / Esc

Printer-friendly Version

Interactive Discussion 